\title{
Believes versus evidence-based regio-orientation in the structure assignment of pyrazolo[1,5-a]pyrimidines
}

\author{
Mosaad Sayed Mohamed ${ }^{1}$, Asmaa Mahmoud Mahmoud ${ }^{2 *}$ \\ ${ }^{1}$ Professor of Pharmaceutical Organic Chemistry, Faculty of Pharmacy, Helwan University, Helwan, Egypt. \\ ${ }^{2}$ Assistant Lecturer of Pharmaceutical Organic Chemistry, Faculty of Pharmacy, Helwan University, Helwan, Egypt.
}

\section{ARTICLE INFO \\ Received on: 12/04/2019 \\ Accepted on: 10/09/2019 \\ Available online: 04/11/2019}

\section{Key words:}

Regio-orientation, regioselectivity,

3(5)-Aminopyrazoles, pyrazolo[1,5-a]pyrimidines,

1,3-bielectrophilic reagents, symmetrical, unsymmetrical, exocyclic $\mathrm{NH}_{2}$, endocyclic NH.

\begin{abstract}
This review aims to focus and highlight the regio-orientation and regioselectivity of the reactions of 3(5)-aminopyrazoles with 1,3-bielectrophilic reagents that lead to the formation of pyrazolo[1,5-a]pyrimidines. To clarify the significance of regio-orientation, reactions of 3(5)-aminopyrazoles with symmetric 1,3-bielectrophilic reagents such as acetylacetone and malononitrile are also included. The comparable nucleophilicity of the exocyclic $\mathrm{NH}_{2}$ group and endocyclic $\mathrm{NH}$ in 3(5)-aminopyrazoles is considered as it causes literature controversy associated with regio-orientation of the substituents on the pyrimidine ring of pyrazolo[1,5-a]pyrimidine when unsymmetrical 1,3-bielectrophilic reagent reacts with 3(5)-aminopyrazole. To the best of our knowledge, this review would be the first collective and confined report to the regio-orientation of pyrazolo[1,5-a]pyrimidines.
\end{abstract}

\section{INTRODUCTION}

\section{The medicinal value of pyrazolo[1,5-a]pyrimidines}

Being purine analogs, the chemistry of pyrazolo[1,5-a] pyrimidines has been extensively investigated. Such compounds have diverse pharmacological, medicinal, and pharmaceutical value. Zaleplon ${ }^{\circledR}$, Ocinaplon ${ }^{\circledR}$, Indiplon ${ }^{\circledR}$, and Lorediplon $^{\circledR}$ are pyrazolo[1,5-a]pyrimidine analogs that act as GABA A receptor agonists and used as sedative, hypnotic, anxiolytic, and in the treatment of insomnia (Ancoli-Israel et al., 1999; Chilman-Blair et al., 2003; Neubauer, 2005; d'Aniello et al., 2015). Dinaciclib ${ }^{\circledR}$ inhibits cyclin-dependent kinases and evaluated in clinical trials for various cancer indications (Parry et al., 2010). Anagliptin ${ }^{\circledR}$ is

"Corresponding Author

Asmaa Mahmoud Mahmoud, Assistant Lecturer of Pharmaceutical Organic Chemistry, Faculty of Pharmacy, Helwan University,

Helwan,Egypt.E-mail:asmaamahmoud@pharm.helwan.edu.eg used for the treatment of type 2 diabetes mellitus in Japan (Ervinna et al., 2013).

Pyrazophos is used as a fungicide and an insecticide (de Waard, 1974). PHTPP ${ }^{\circledR}$ (Chan et al., 2014; Iorga et al., 2018) is used in scientific research as a nonsteroidal highly selective antagonist of $\beta$-estrogen receptors. DPA714 ${ }^{\circledR}$ is a radiopharmaceutical for imaging translocator protein in living systems using positron emission tomography (PET), and its radiolabeled analog with $\mathrm{C}-11$, DPA $713^{\circledR}$, is used as a radiotracer for imaging the TSPO using PET (Fig. 1) (Banister et al., 2012; Reynolds et al., 2010; Selleri et al., 2001).

\section{Our approach to handling the subject}

Regio-orientation assignment of substituents on the pyrazolo[1,5-a]pyrimidines, compounds formed via condensation of 3-aminopyrazoles with 1,3-bielectrophilic reagents requires: first, to investigate the chemical reactivity of 3(5)-aminopyrazoles with special emphasis on the sites of the nucleophilicity of such compounds $\left[\mathrm{NH}_{2}\right.$ (exocyclic) and $\mathrm{NH}$ (ring)]. Second, classification 


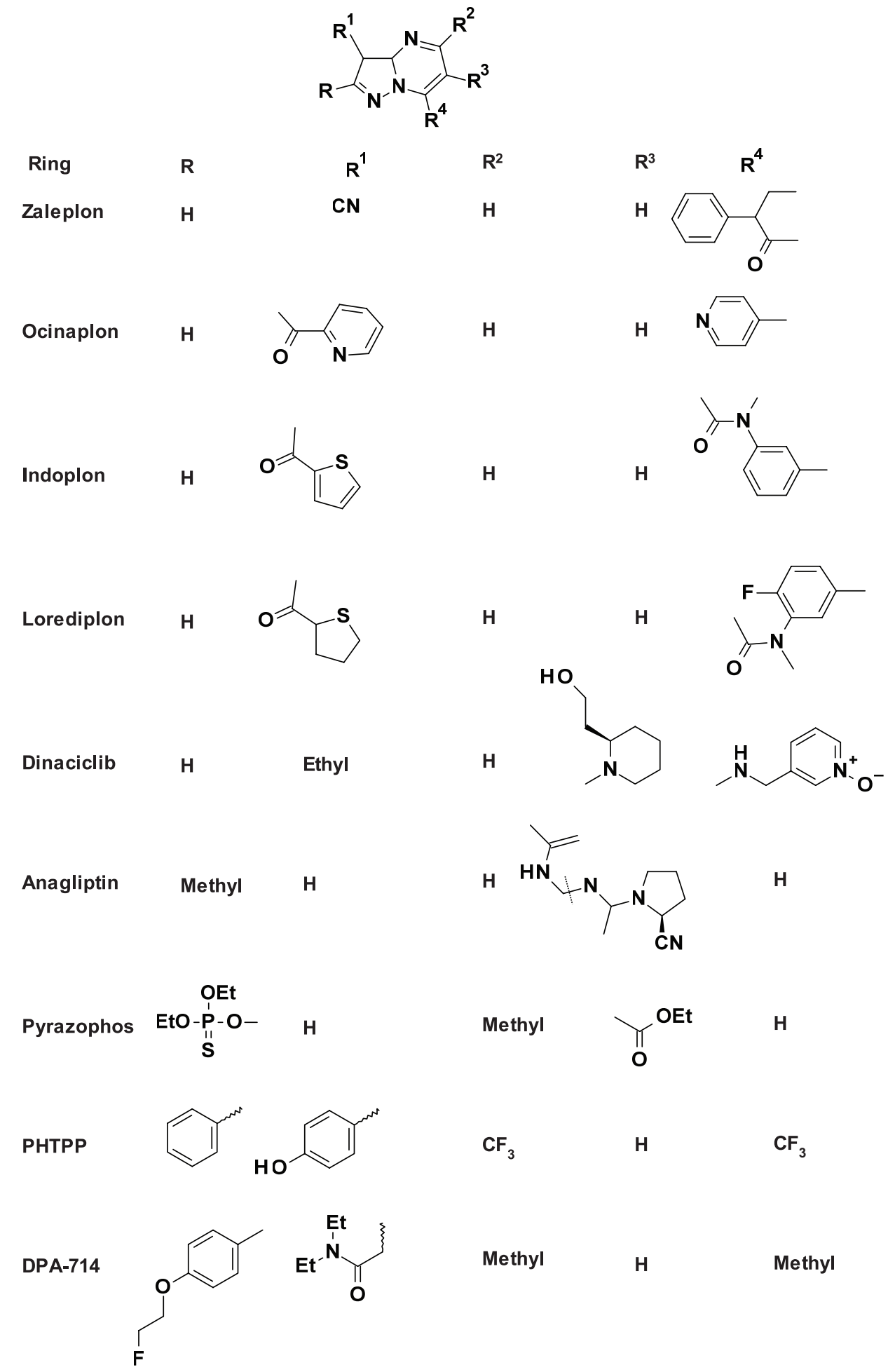

Figure 1. The general structural formula for pyrazolo[1,5-a]pyrimidines of pharmacological, medicinal, and pharmaceutical value.

of the bielectrophilic reagents and locating the more electrophilic and less steric hindered site according to the rules of chemistry. Third, to assign the regio-orientation based on just believes, assumption, or weighing previous literature reports. In addition to insufficient or unreliable spectral data or irrelevant unambiguous synthesis are considered. Most importantly, evidence-based regioorientation assignment of substituents around the pyrimidine ring using X-ray crystallography, ${ }^{1} \mathrm{H}-{ }^{15} \mathrm{~N}$ Heteronuclear Multiple Bond Correlation, Nuclear Overhauser Effect (NOE) effect, and relevant unambiguous synthesis are highlighted. 


\section{COMPARABLE REACTIVITY OF THE EXOCYCLIC AND ENDOCYCLIC NH/NH IN 3(5)-AMINOPYRAZOLES}

\section{3(5)-aminopyrazole tautomers}

The literature survey indicates that 3(5)-aminopyrazoles of type 1 have three nucleophilic centers, namely, exocyclic $\mathrm{NH}_{2}$, endocyclic $\mathrm{NH}$, and the $3^{\circ} \mathrm{N}$ of the pyrazole ring. In addition to the fourth one if, and only if, the fourth position is unsubstituted. Such nucleophilicity could be referred to the behavior of the molecule as an enamine (Fig. 2).

\section{Relative nucleophilicity of the amino and imino groups}

Noteworthy, some authors believed (no evidence has been provided) that the endocyclic NH group is the most nucleophilic center in these compounds, although the experimental results (Al-Shiekh et al., 2004; Al-Omran and El-Khair, 2006; Dawood et al., 2005; Ege and Gilbert, 1979a; Ege et al., 1984; Elagamey et al., 1986; Elnagdi et al., 1976; 1981; El-Ghandour Ahmed Hafez et al., 1992; Joshi et al., 1983; Kočevar et al., 1976) showed that such compounds could be successfully diazotized at the cost of the

a)

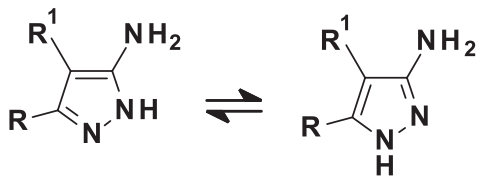

b)
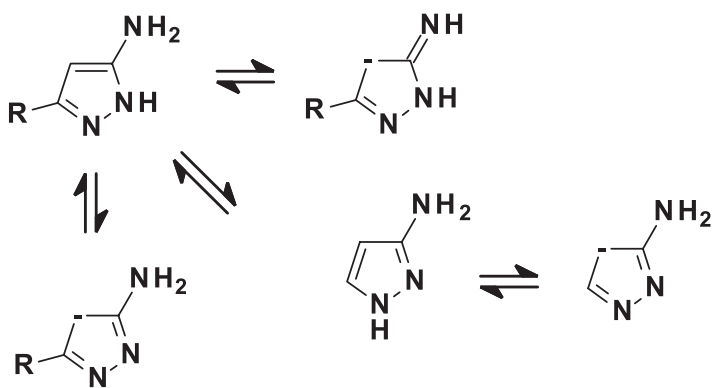

exocyclic $\mathrm{NH}_{2}$ group which is consistent with the fundamentals of chemistry (Scheme 1).

Reactivity of aminopyrazoles in diazotization and coupling was discussed in 2009 (Moyano et al., 2008) and the pattern demonstrated previously was confirmed (Moyano et al., 2008).

Diazotization (Ege and Gilbert, 1979b; Wu et al., 2005) of 5-aminopyrazole derivative (3) gave diazo-3-(methylsulphonyl)1H-pyrazole (4) that reacted with arylisocyanates in $\mathrm{CH}_{2} \mathrm{Cl}_{2}$ to give the corresponding pyrazolo[1,5-a]tetrazine analogs 5 (Scheme 2).

\section{Relative nucleophilicity of $\mathrm{NH}_{2}$ group}

Acylation of 5-aminopyrazole derivative (6) afforded a mixture of 3(5)-aminoacylpyrazole (7) and the two acyl analogs (8) and (9) (Scheme 3). Michon et al. reported that the major amide derivative isolated was due to the acylation reaction of exocyclic amino group (7) of percent yield (24\%), while the percent yields of the other amides (8) and (9), afforded from the acylation of the endocyclic nitrogen, were (13\%) and (6.5\%), respectively (Graubaum, 1993; Michon et al., 1995; Quiroga et al., 2008).

Acylation (El-Emary et al., 2002) is restricted to the $5-\mathrm{NH}_{2}$ group, especially when the endocyclic $\mathrm{NH}$ is blocked. Thus, 5-amino-1-substituted pyrazole analogs 10 gave the corresponding 5-acylamino derivatives when different acylating reagents were used (Scheme 4).

Isocyanates and isothiocyanates, respectively, reacted with aminopyrazoles 14 giving the corresponding urea derivatives 15 (Bagley et al., 2006; Schenone et al., 2004; Winters et al., 1984) (Scheme 5).

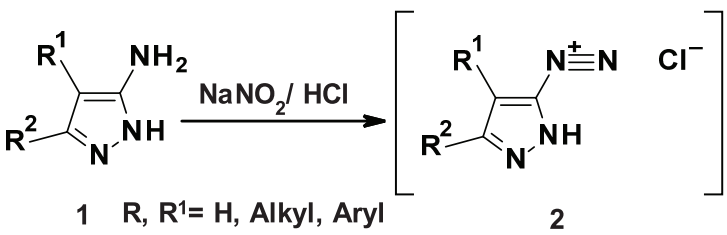

Figure 2. a) 4-substituted pyrazole b) unsubstituted pyrazole

Scheme 1.

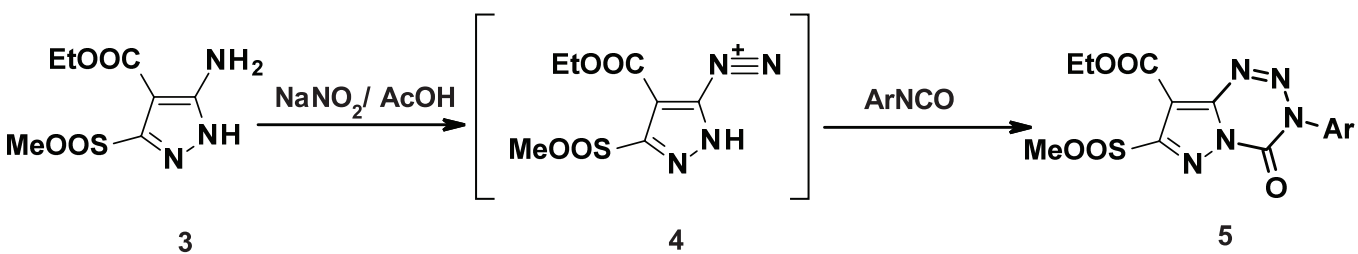

Scheme 2 .

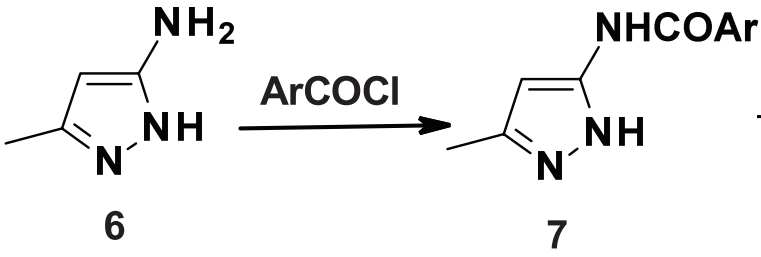

$(24 \%)$

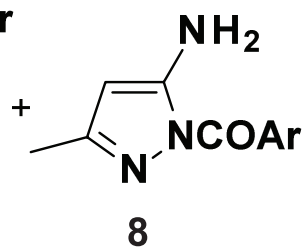

$(13 \%)$

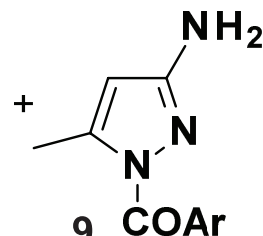

$(6.5 \%)$

Scheme 3 . 


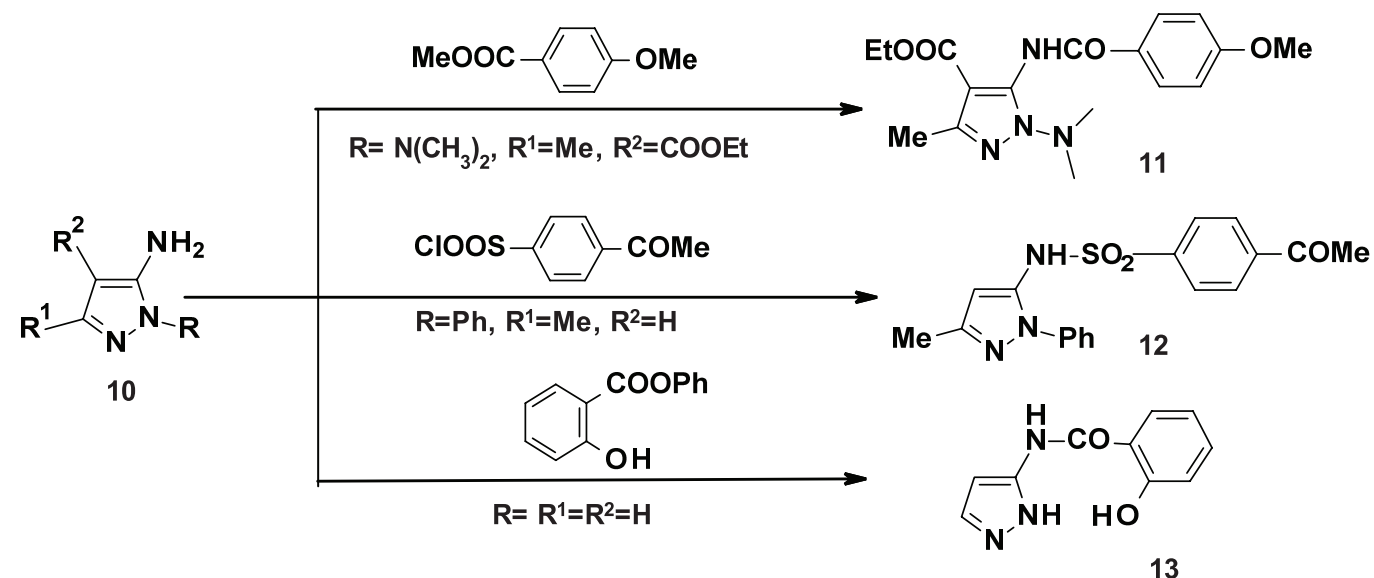

Scheme 4.

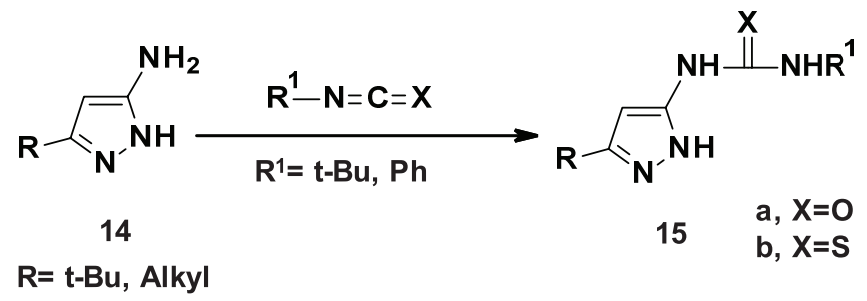

Scheme 5.

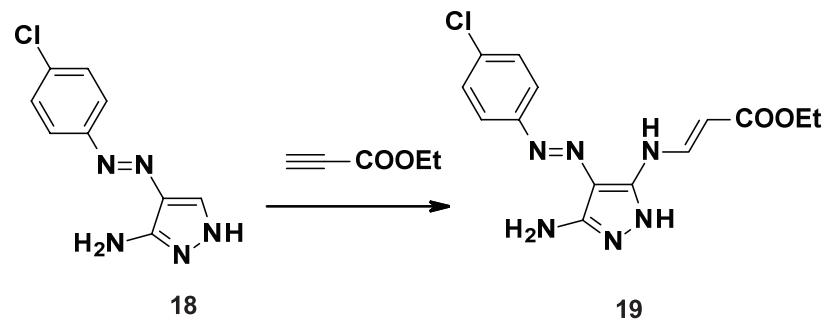

Scheme 7.<smiles></smiles>

Scheme 6.

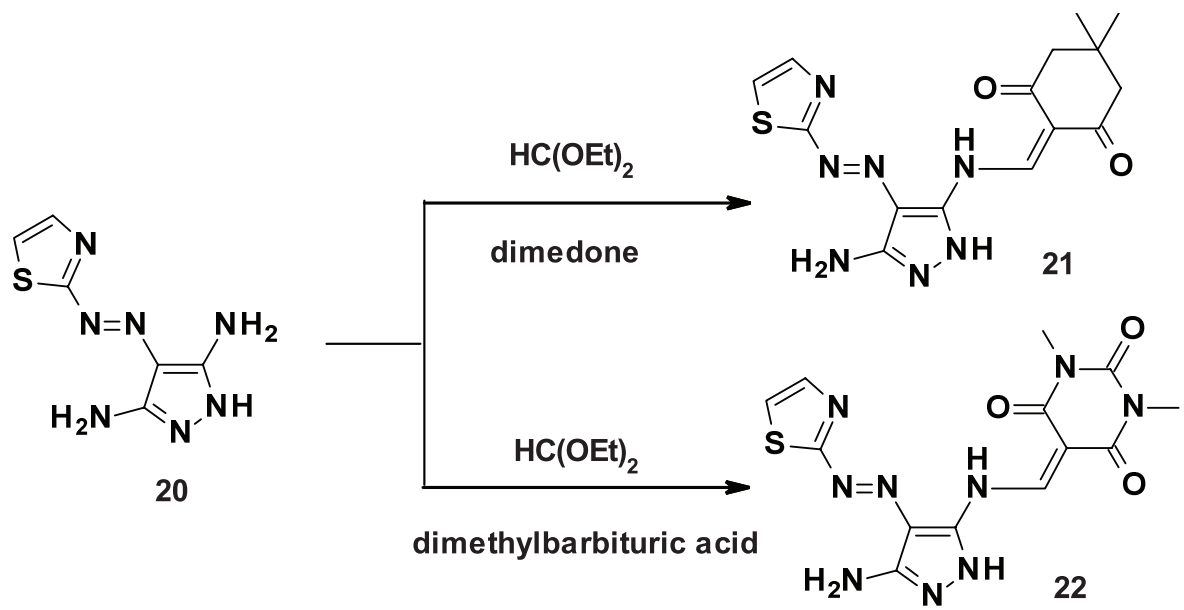

Scheme 8 . 


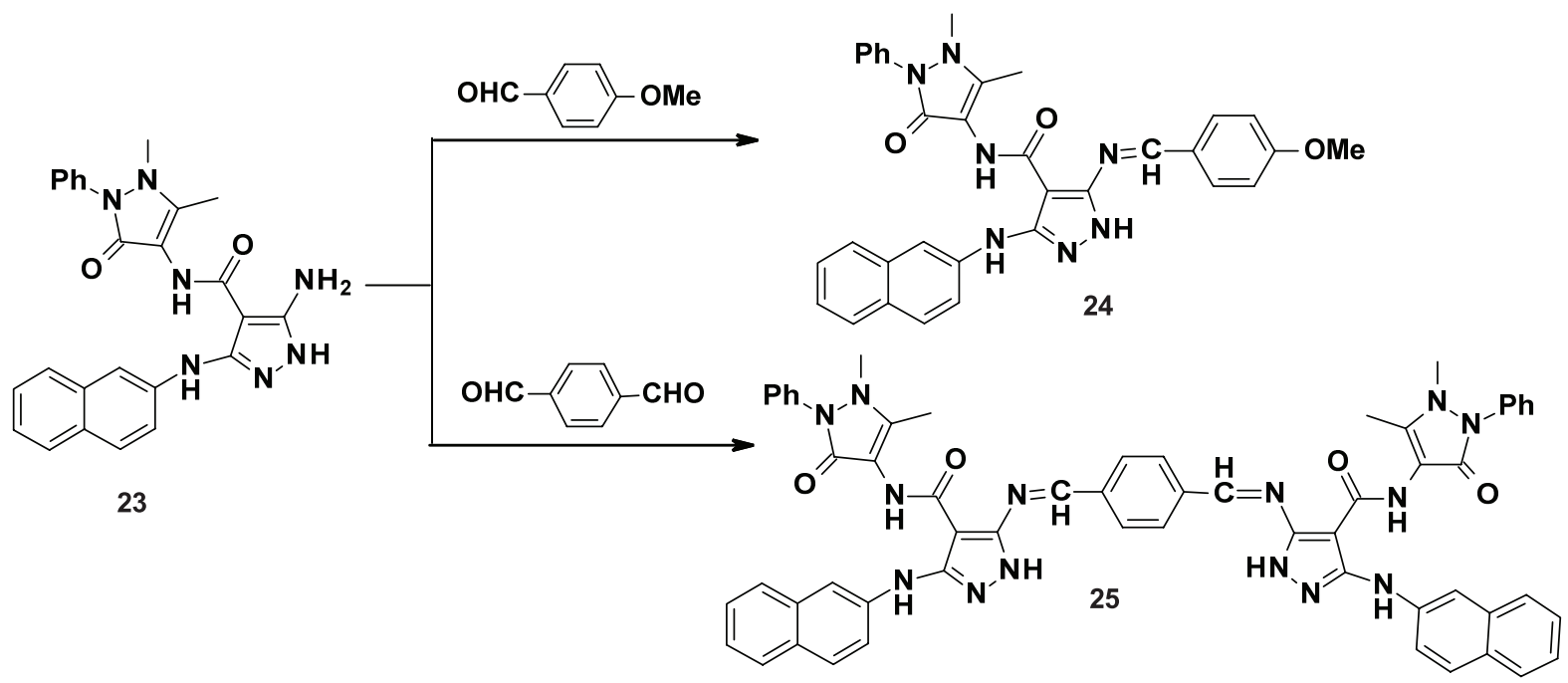

Scheme 9.

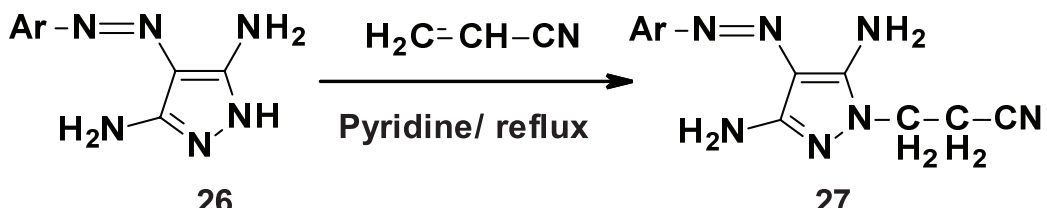

$\mathrm{Ar}=\mathrm{C}_{6} \mathrm{H}_{5}, 4-\mathrm{Me}-\mathrm{C}_{6} \mathrm{H}_{4}$

Scheme 10.

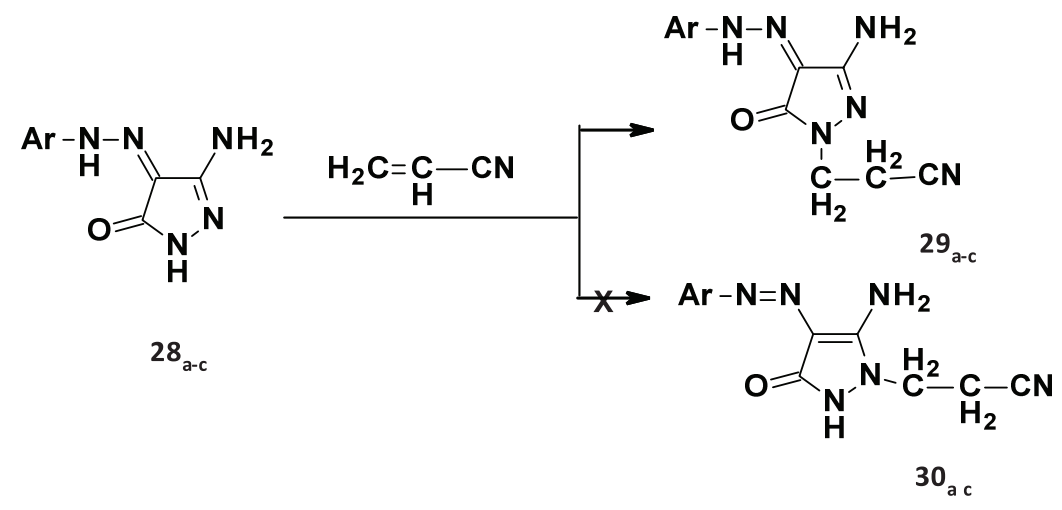

Scheme 11.

Ho and Yao (2003) reported that heating 3-aminopyrazolo[3,4-d]pyrimidine derivative (16) with diethyl malonate at $150^{\circ} \mathrm{C}$ gave ethyl2-[(4-methyl-6-phenylpyrazolo[3,4-d] pyrimidinyl)amido]ethanoate (17) (Scheme 6).

A further evidence for the relative higher nucleophilicity of the exocyclic $\mathrm{NH}_{2}$ group in 3(5)-aminopyrazole derivatives has been reported by Al-Zaydi (2009a) since the author isolated the ethyl (pyrazol-5-ylamino)acrylate derivative (19) via reaction of 5-aminopyrazole derivative (18) with ethyl propiolate under microwave irradiation (Scheme 7).
Furthermore, El-Mekabaty and Hasel (2015) reported that the condensation of 3,5-diaminopyrazle derivative (20) with triethylformate and certain active methylene containing compounds, dimedone, and diethyl barbituric acid led to the isolation and identification of the two intermediates (21), (22) (Scheme 8).

Recently, Helal et al. (2017) reported that reaction of 5-aminopyrazole derivative (23) with 4-methoxybenzaldehyde and terenaphthaldehyde afforded the corresponding mono and bis-(azomethine) derivatives (24) and (25). Noteworthy, the 


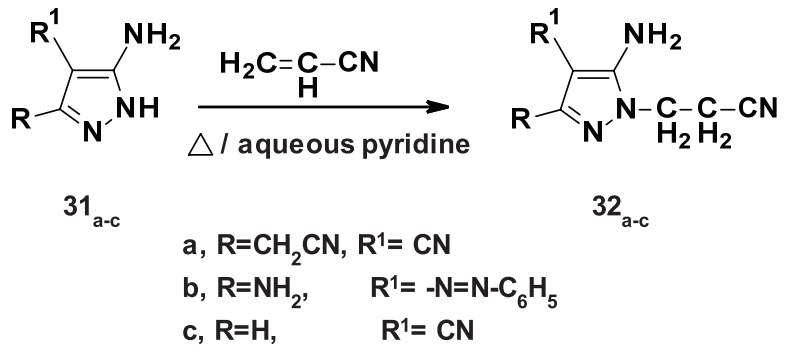

Scheme 12.
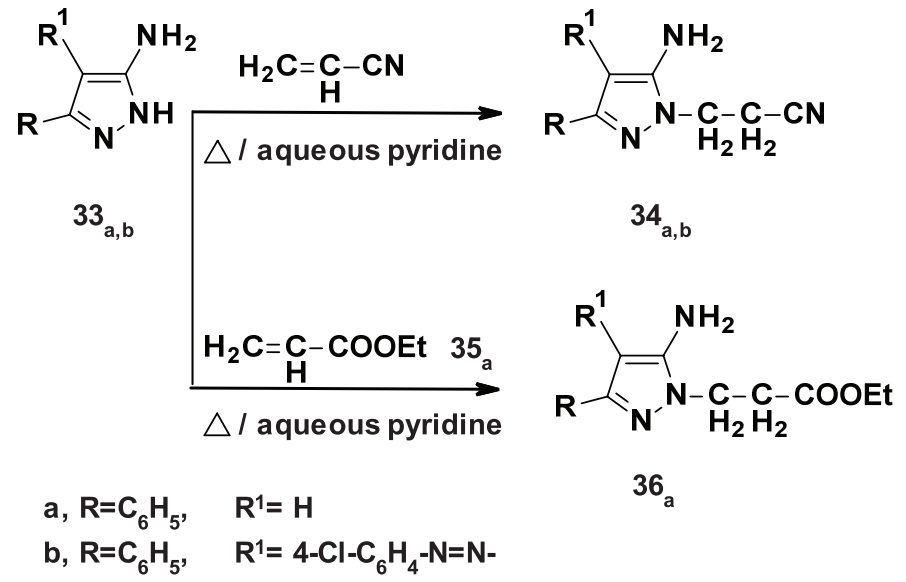

36

Scheme 13

reaction, in both cases, occurs on the exocyclic $\mathrm{NH}_{2}$ group (Scheme 9).

Elnagdi and Abd Allah (1973) reported that 3,5-diaminopyrazole derivatives 26 reacted with acrylonitrile in refluxing pyridine to yield the corresponding 1- $\beta$-cyanoethyl derivatives 27 (or possible tautomers) (Scheme 10).

Elnagdi et al. (1974) reported that treatment of 4-arylhydrazono-3-amino-2-pyazolin-5-ones 28 with acrylonitrile afforded 3-amino-1- $\beta$-cyanoethyl-4-arylhydrazone2 -pyazolin-5-ones, the mono- $\beta$-cyano derivatives, $29_{\text {a-c }}$ (or possible tautomers) rather than the isomeric compounds $30_{\mathrm{a}-\mathrm{c}}$ (Scheme 11).

In the same year, in 1974, Elnagdi (1974) reported that refluxing the 5-aminopyrazole derivative $31_{\mathrm{a}-\mathrm{c}}$ with acrylonitrile, in aqueous pyridine, the corresponding 5-amino-1-( $\beta$-cyanoethyl) pyrazole derivatives $32_{\text {a-c }}$ were obtained (Scheme 12).

In another publication, Elnagdi et al. (1975) reported that reaction of 5-aminopyrazole analogs $33_{\mathrm{a}, \mathrm{b}}$ with acrylonitrile in aqueous pyridine at reflux, afforded the corresponding 5-amino-1( $\beta$-cyanoethyl)pyrazoles $34_{\mathrm{a}, \mathrm{b}}$. Also, the condensation of 5-amino3-phenylpyrazole (35) with ethyl acrylate, in refluxing aqueous pyridine gave the corresponding 5-amino-1- $\beta$-(ethoxycarbonyl) ethylpyrazole derivative (36) (Scheme 13).

Elnagdi et al. (1975) continued their previous work (Elnagdi, 1974; Elnagdi and Ohta, 1973; Elnagdi and Allah, 1973; Elnagdi et al., 1974; 1975a) which involved cyanoethylation of 5 -aminopyrazoles that gave 5-amino-1- $\beta$-cyanoethyl pyrazole

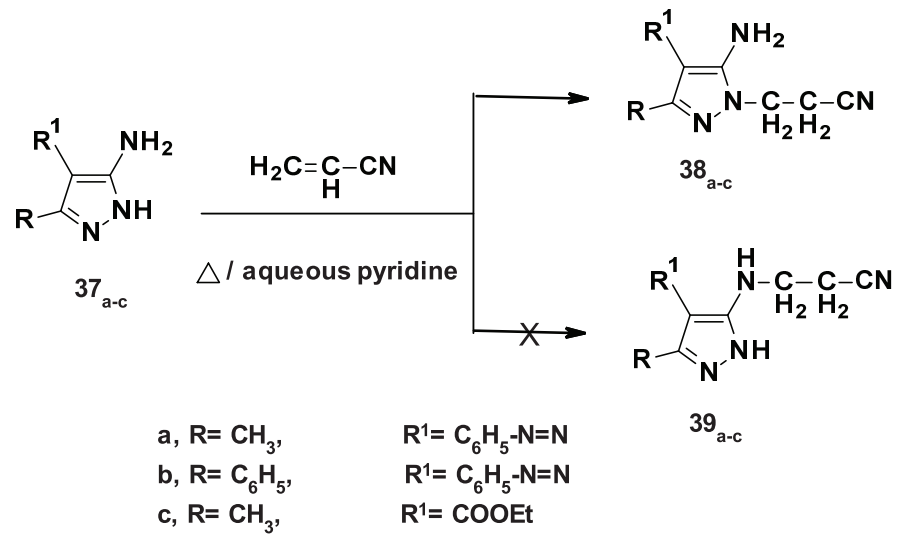

Scheme 14

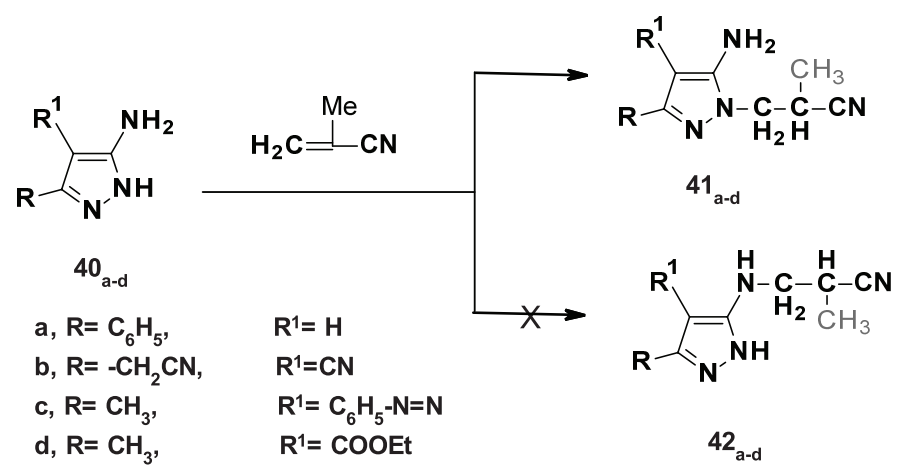

Scheme 15.

derivatives. Thus, the reaction of 5-aminopyrazole $37_{\mathrm{a}-\mathrm{c}}$ with acrylonitrile in aqueous pyridine afforded the corresponding 5-amino-1- $\beta$-cyanoethyl pyrazole analogs $38_{\mathrm{a}-\mathrm{c}}$ rather than 5-cyanoethylamino analogs 39 a-c (Scheme 14).

Analogously, 5-aminopyrazole analogs reacted with methyl acrylonitrile to afford the corresponding 5-amino-1- $\beta$-cyanoisopropylpyazole $41_{\mathrm{a}-\mathrm{d}}$ rather than the 5 - $\beta$-cyanoisopropylamine analogs (Scheme 15) (Elnagdi Mohamed et al., 1975).

Elnagdi et al. (1977) isolated and identified the product obtained from the reaction of 3,5-diaminopyrazole derivative (43) with ethylethoxymethylenecyanoacetate, in refluxing methanol, as the corresponding aminomethylene derivative (44) (Scheme 16).

Noteworthy, quoted as reported by Elnagdi et al., at that time, "since the previous result indicate that ring $\mathrm{N}-1$ is the most electrophilic center in the molecule the formation of aminomethylene derivative (2) might be assumed to proceed via intermediate formation of the ring $\mathrm{N}-1$ alkylated product. The later then isomerizes into 2 . The ready isomerization of 1- $\beta$-cyanomethylene-5-aminopyrazoles into the corresponding 5-aminomethylene derivatives has been recently reported (Reimlinger et al., 1970)."

In the same article, the authors reported that when (43) was heated under reflux in $\mathrm{AcOH}$, the corresponding 3,5-diacetamido-4-phenylazopyrazole (45) was obtained (Scheme $17)$, notice, how these results are contradicting. 
Ph<smiles>N=Nc1c(N)n[nH]c1N</smiles><smiles>CCOC=C(C#N)COCC</smiles>

43

Scheme 16.<smiles>Nc1n[nH]c(N)c1/N=N/c1ccccc1</smiles>

43

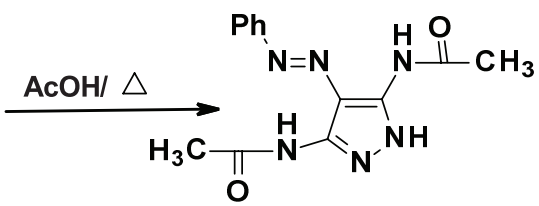

45

Scheme 17.

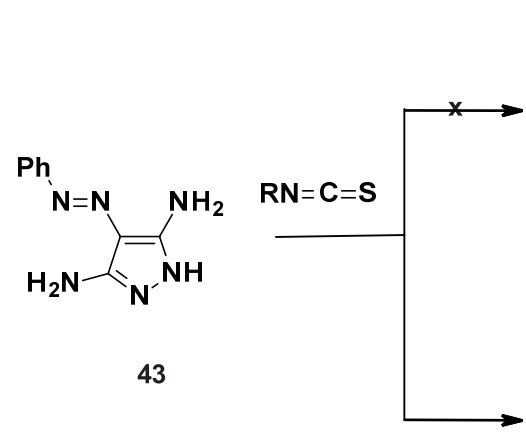

Ph

$46(3)$
Scheme 18.

In contrast, Elnagdi et al., in the same article, quoted as reported (Reimlinger et al., 1970) "Although 5-aminopyrazoles were reported to react with isocyanate to yield compounds similar to structure 2 where the addition would involve the amino nitrogen (Reimlinger et al., 1970; Vogel and Troxler, 1975; Dymek et al., 1965). We (Elnagdi et al.) obtained products that proved to be 3. " That is involved in the endocyclic N-1 nitrogen (Scheme 18).

Elnagdi et al. (1978) reported that 3,5-diaminopyrazole (47) reacted with acrylonitrile in refluxing aqueous pyridine to afford the corresponding 3,5-diamino-1- $\beta$-cyanoethyl pyrazole (Scheme 19).

\section{FACTORS DETERMINE THE REGIO-ORIENTATION OF PYRAZOLO[1,5-A]PYRIMIDINES}

Literature survey indicated that regio-orientation in pyrazolo[1,5-a]pyrimidines are controlled by the comparable nucleophilicity of the exocyclic $\mathrm{NH}_{2}$ group and the endocyclic $\mathrm{NH}$ group of the pyrazole ring. As we aforementioned, most authors reported that the isolation of reaction products indicated

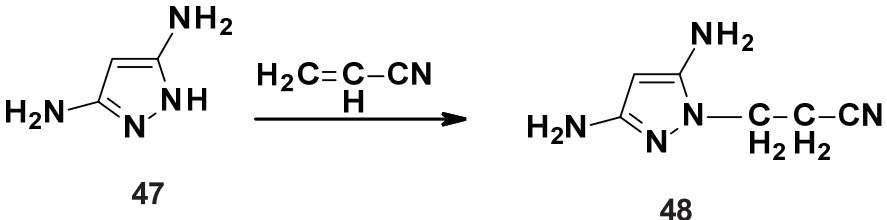

Scheme 19.

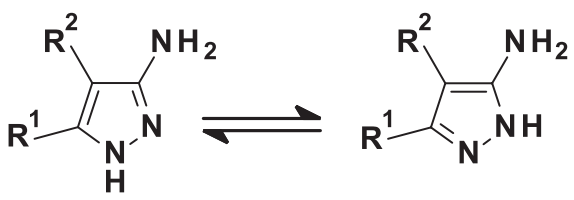

49

50

$R^{1}=\mathrm{H}$, Me, 4-Me- $\mathrm{C}_{6} \mathrm{H}_{5}, \mathrm{Ph}, 4-\mathrm{MeOC}_{6} \mathrm{H}_{4}, 4-\mathrm{Br}-\mathrm{C}_{6} \mathrm{H}_{4}, 4-\mathrm{Cl}-\mathrm{C}_{6} \mathrm{H}_{4}$ $\mathrm{R}^{2}=\mathrm{CN}, \mathrm{SCN}, 4-\mathrm{MeOC}_{6} \mathrm{H}_{4}, \mathrm{Ph}, 4-\mathrm{Cl}-\mathrm{C}_{6} \mathrm{H}_{4}, 3-\mathrm{Br}_{-} \mathrm{C}_{6} \mathrm{H}_{4}$

Figure 3. Tautomerism of some 3(5)-aminopyrazoles.

the relative higher nucleophilicity of the exocyclic $\mathrm{NH}_{2}$. On the other hand, some other authors believed that the endocyclic $\mathrm{NH}$ group is the most nucleophilic center in such molecules and consequently assigned their reaction products as N1substituted 5-aminopyrazoles. In 2014, tautomerism of certain 3(5)-aminopyrazoles has been studied (Emelina et al., 2014) by ${ }^{1} \mathrm{H}$ and ${ }^{13} \mathrm{C}$ NMR in solution, cross-polarization and magic-angle spinning ${ }^{13} \mathrm{C}$ NMR in the solid-state, and ab initio quantum chemical calculations (B3LYP/6-31G**). The results proved that the maximum electron density in tautomers 49 and 50 is localized on the exocyclic amino nitrogen atom. The negative charge in the pyrazole ring is localized mainly on the nitrogen atoms, in going from the gas phase to DMSO solution, the charge on $\mathrm{NH}$ remains almost unchanged, whereas the charge on N2 increases in both tautomers (Fig. 3).

The second factor that controls regio-orientation in pyrazolo[1,5-a]pyrimidine structures is the comparable electrophilicity of the 1,3-bielectrophilic reagents. The following cases could be summed: 1) When the 1,3-dielectrophilic reagent is a symmetrical molecule, such as acetylacetone or malononitrile, regio-orientation is nonsense, and should not be considered. 2) when the 1,3-dielectrophilc reagent is unsymmetrical such as EAA, ECA, unsymmetrical 1,3-diketones or $\beta$-ketocycloalkanes, $\alpha, \beta$-unsaturated carbonyl compounds, $\alpha, \beta$-unsaturated nitriles, 


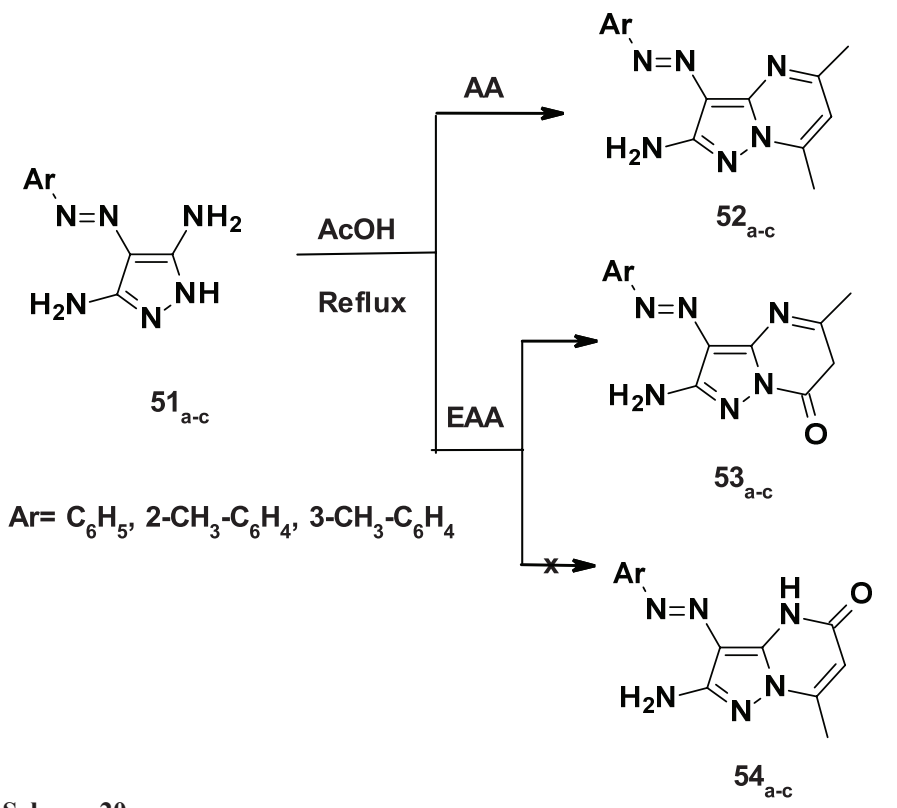

Scheme 20.

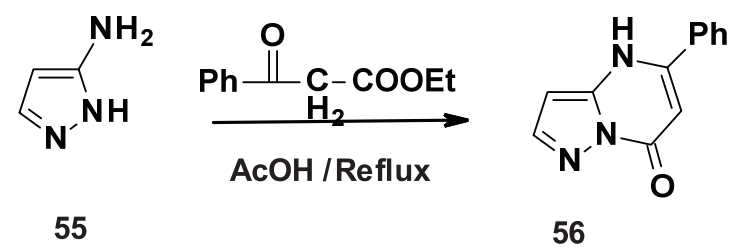

Scheme 21.

enaminonitriles or ketone dithioacetals, regio-orientation should be carefully considered. That is the comparable electrophilicity of the 1,3-dielectrophile is decided on the basic rules of chemistry and the regio-orientation of the reaction product should be proved by reliable advanced spectroscopic techniques such as NOE, ${ }^{1} \mathrm{H}-{ }^{15} \mathrm{~N}$ NMR spectroscopy, and X-ray crystallography data.

\section{SYNTHETIC ROUTES TO PYRAZOLO[1,5-A] PYRIMIDINE}

General reactions of 3(5)-aminopyrazole derivatives with dielectrophilic reagents are the most common routes to synthesize the pyrazolo[1,5-a]pyrmidines. Such reactions when involving symmetrical 1,3-dielectrophilic reagent lead to a single product of pyrazolo[1,5-a]pyrimidine. On the other hand, when the reaction involves unsymmetrical 1,3-bielectrophilic reagent, unambiguous assignment of the regio-orientation of the product requires extensive investigations and evidence-based structural elucidation rather than believes and assumptions. Also, insufficient or unreliable spectral data and even irrelevant independent routes of synthesis could not be conclusive. However, advanced spectral techniques such as ${ }^{1} \mathrm{H}-{ }^{15} \mathrm{~N}$ NMR and X-ray crystallography, in addition to isolation and identification of associated reaction intermediate could be conclusive. In the following paragraphs, the synthesis of pyrazolo[1,5-a]pyrimidines via reactions of 3(5)-aminopyrazoles with 1,3-bielectrophilic reagents based on literature survey is reported.

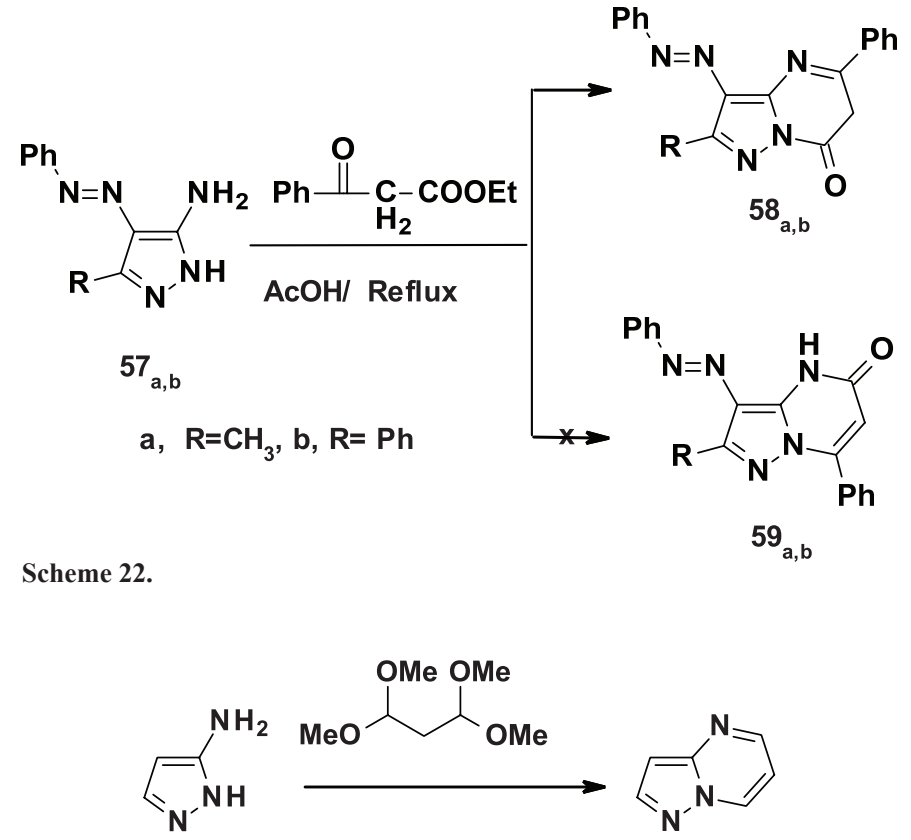

Scheme 23.

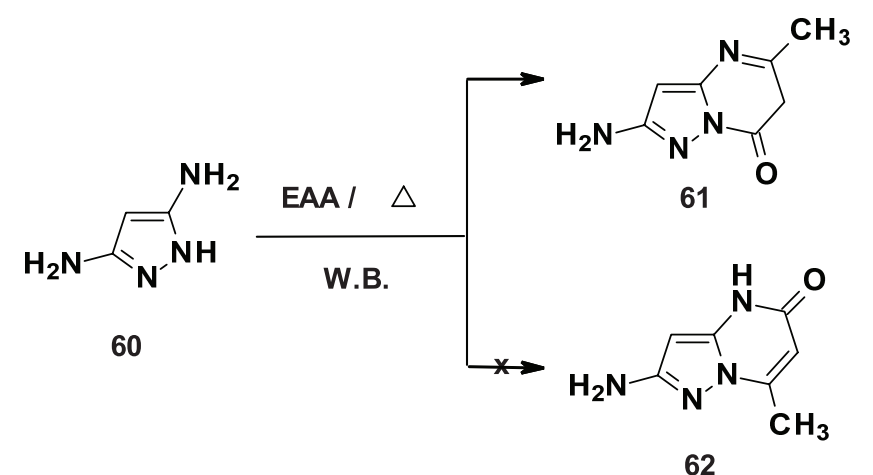

Scheme 24.

\section{Reactions of 3(5)-aminopyrazoles with 1,3-dicarbonyl compounds}

Elnagdi et al. (1975) reported that 3,5-diamino-4phenylazopyrazoles $\left(51_{\mathrm{a}-\mathrm{c}}\right)$ reacted with acetylacetone at reflux in $\mathrm{AcOH}$ to afford the corresponding pyrazolo[1,5-a]pyrimidine derivatives $52_{\mathrm{a}-\mathrm{c}}$. On the other hand, $\left(51_{\mathrm{a}-\mathrm{c}}\right)$ reacted with EAA under the same conditions to afford the pyrazolo[1,5-a]pyrimidine analogs $53_{\mathrm{a}-\mathrm{c}}$ rather than the regio-isomer $54_{\mathrm{a}-\mathrm{c}}$. The structure of the regio-isomer $53_{\mathrm{a}-\mathrm{c}}$ was supported by traditional elemental analysis and interpretation of the IR spectral data in addition to previously reported (Reimlinger et al., 1970) reactions, in 1970 (Scheme 20) which involved the reaction of 5-aminopyrazole (55) with ethyl benzoylacetate to afford the corresponding pyrazolo[1,5-a]pyrimidine derivative (56) (Scheme 21).

Also, Elnagdi et al. (1975) reported that reaction of the 5-aminopyrazole derivatives $\left(57_{\mathrm{a}, \mathrm{b}}\right.$ ) with ethyl benzoylacetate, in refluxing $\mathrm{AcOH}$ afforded the corresponding pyrazolo[1,5-a] 


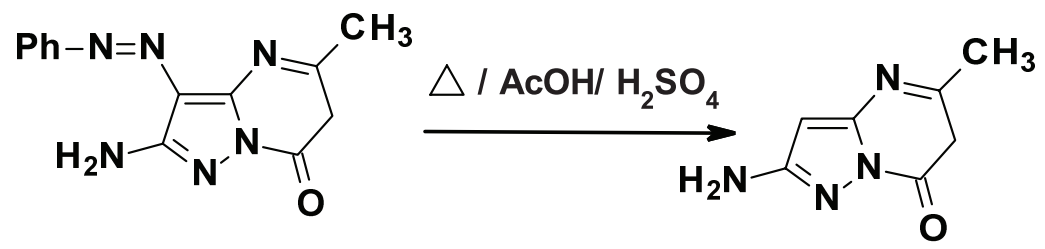

63

Scheme 25.<smiles>COC(CC(C)=O)CC(C)C</smiles><smiles>C=C1CCCCC1=O</smiles>

Scheme 26.

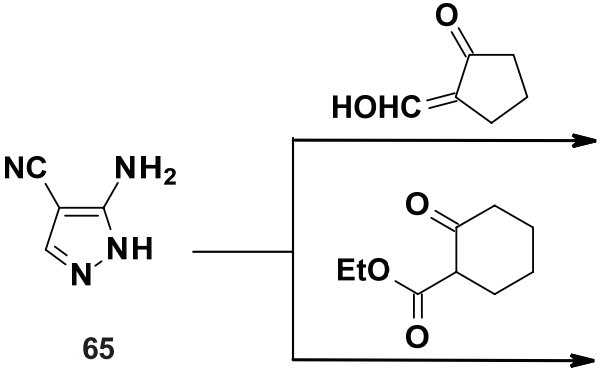

Scheme 27.

pyrimidine derivatives $\left(58_{\mathrm{a}, \mathrm{b}}\right)$ rather than the regio-isomer $\left(59_{\mathrm{a}, \mathrm{b}}\right)$ (Scheme 22).

Lynch et al. (1975) prepared the parent pyrazolo[1,5-a] pyrimidine by condensation of 5-aminopyrazole with malondialdehyde-tertamethylacetal in excellent yield (Scheme 23).

Elnagdi et al. (1978) consistent with the abovementioned results reported that when 3,5-diaminopyrazole (60) was heated with EAA in WB (in the absence of solvent), the corresponding pyrazolo[1,5-a]pyrimidine derivative (61) was obtained rather than the regio-isomer (62) (Scheme 24). Structure of the regio-isomer (61) was proved (Elnagdi et al., 1975b) by ${ }^{1} \mathrm{H}$ NMR and independent synthesis of (61) by decoupling of the phenylazo group from the previously prepared 2-amino-6,7dihydro-5-methyl-7-oxo-3-phenylazopyrazolo[1,5-a]pyrimidine (63) (Scheme 25).

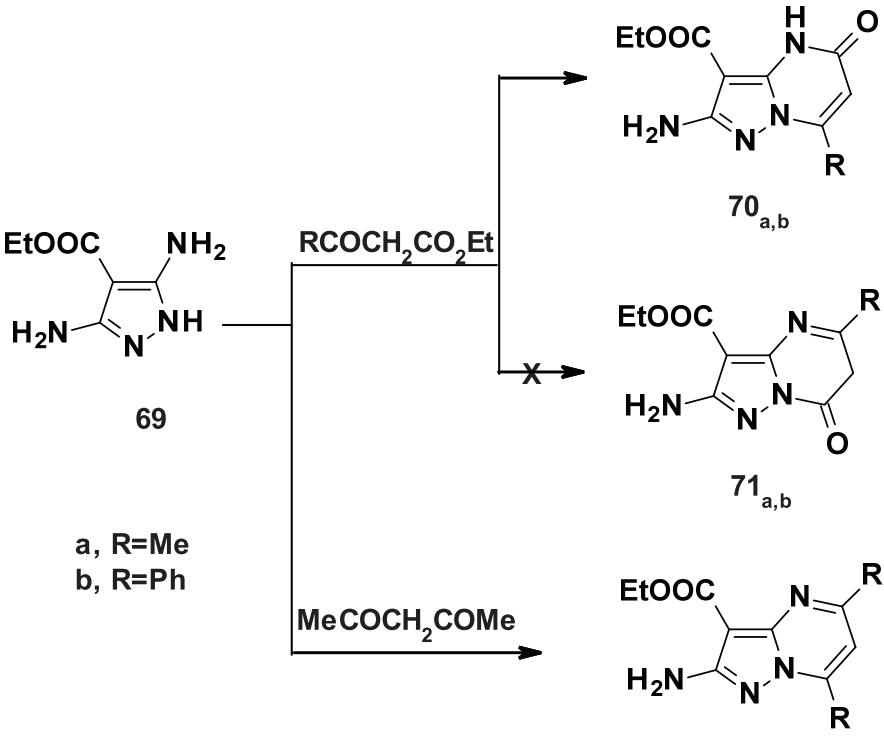

72

Scheme 28.

Bajwa and Skyes (1979) investigated the condensation of 5-aminopyrazole (55) with $\beta$-ketoacetal (4,4-dimethoxybutan-2-one), in dry toluene containing a catalytic amount of p-toluene sulfonic acid. The condensation of the 4-cyano analog of (65) with 2-hydroxymethylene cyclohexanone, 2-hydroxymethylenecyclopentanone, and with ethoxycarbonylcyclohexanone has been investigated. The reaction of (55) with 4,4-dimethoxybuta-2-one gave the corresponding 


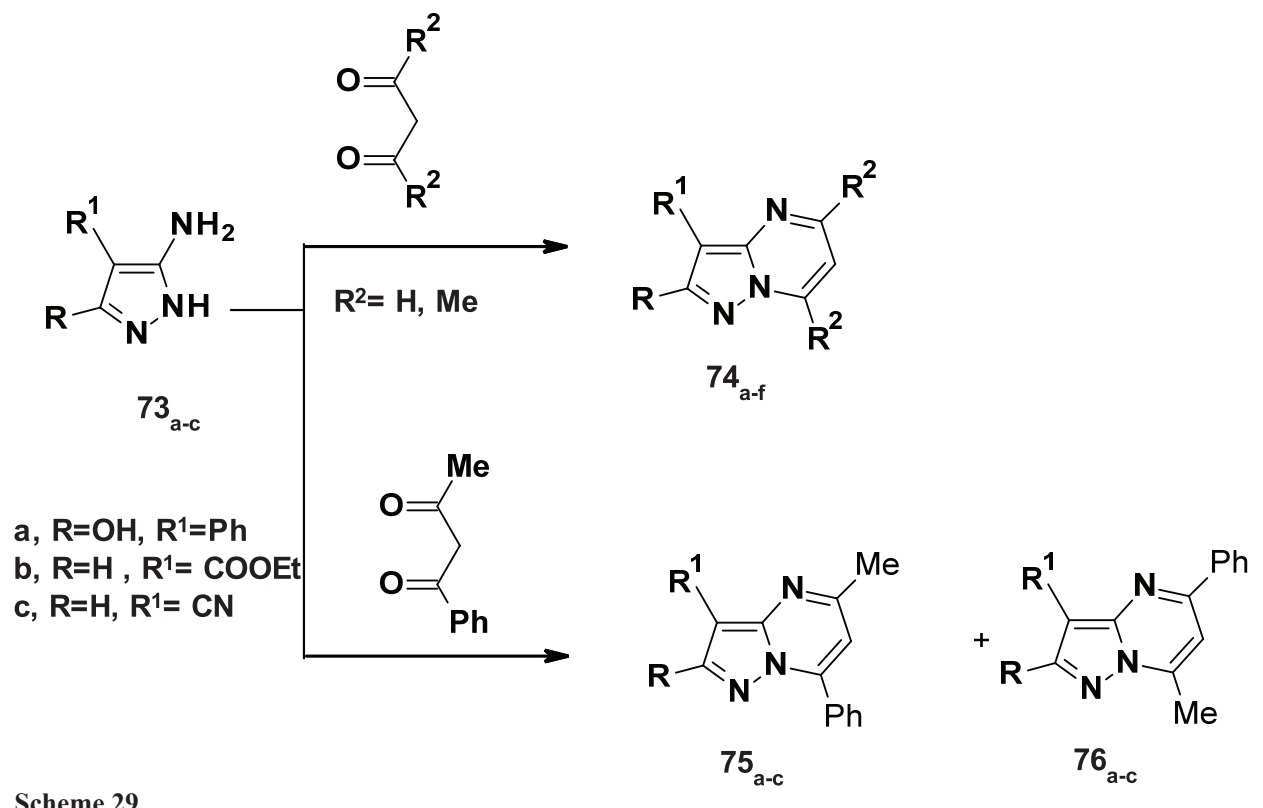

Scheme 29.

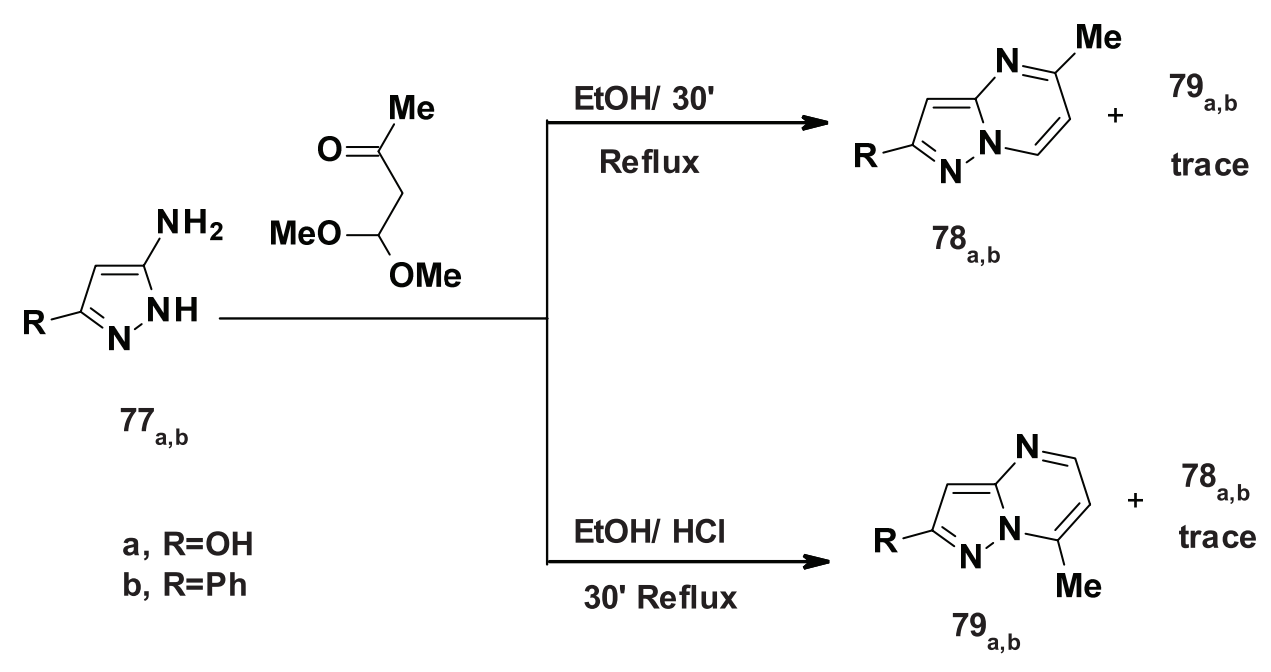

Scheme 30.

two regio-isomer pyrazolo[1,5-a]pyrimidine derivative $\left(64_{\mathrm{a}, \mathrm{b}}\right)$. Similarly, the condensation of (65) with 2-hydroxymethylene cyclohexanone afforded the respective two regio-isomers $\left(66_{\mathrm{a}, \mathrm{b}}\right)$ (Scheme 26).

On the other hand, condensation of the 4-cyanoanalogue of (65) with 2-hydroxymethylenecyclopentanone and with 2-ethoxycarbonylcyclohexanone gave only the angular pyrazolo[5,1-b]pyrimidine regio-isomer (67) and only the linear pyrazolo[5,1-b]pyrimidine (68), respectively (Scheme 27).

The structure of the condensation products $64_{\mathrm{a}, \mathrm{b}}$, $66_{\mathrm{a}, \mathrm{b}}$, (67), and (68) has been distinguished by ${ }^{1} \mathrm{H}$ and ${ }^{13} \mathrm{C} \mathrm{NMR}$ spectroscopy.

Kandeel et al. (1983) including Elnagdi reported that 3,5-diaminopyrazole derivative (69) reacted with EAA or with benzoyl acetoacetate to afford the corresponding pyrazolo[1,5-a] pyrimidine regio-isomer $70_{\mathrm{a}, \mathrm{b}}$ rather than the analogs $71_{\mathrm{a}, \mathrm{b}}$. The reaction of (69) with acetylacetone proceeded as expected to give the corresponding 5,7-diamethylpyrazolo[1,5-a]pyrimidine (72) (Scheme 28).

Maquestiau et al. (1992) reported the preparation of pyrazolo[1,5-a]pyrimidine $74_{\text {a-f }}$ via reaction of 3(5)-aminopyrazoles $73_{\text {a-c }}$ with malondialdehyde bis(dimethylacetal) and with acetylacetone, in refluxing $\mathrm{AcOH}$. On the other hand, reaction of $73_{\mathrm{a}-\mathrm{c}}$ with the unsymmetrical 1-phenyl-1,3-butandione, under the same conditions, afforded a mixture of the two corresponding pyrazolo[1,5-a]pyrimidineregio-isomers $75_{\text {a-c }}$ and $76_{\text {a-c }}$ (Scheme29), structural characterization of the products was based on ${ }^{1} \mathrm{H}$ NMR data and that regio-isomer assignment was confirmed by the magnitude of the corresponding $3 \mathrm{~J}$ and $4 \mathrm{~J}(\mathrm{H}-\mathrm{H})$ coupling constants which is affected by C5-C6/ C7-C6 bond order (Barfield and Chakrabarti, 1969).

Chimichi et al. (1992) described the regioselective synthesis of certain pyrazolo[1,5-a]pyrimidines $78_{\mathrm{a}, \mathrm{b}}$ and $79_{\mathrm{a}, \mathrm{b}}$ via reacting the 5-aminopyrazoles $77_{a, b}$, independently, with 


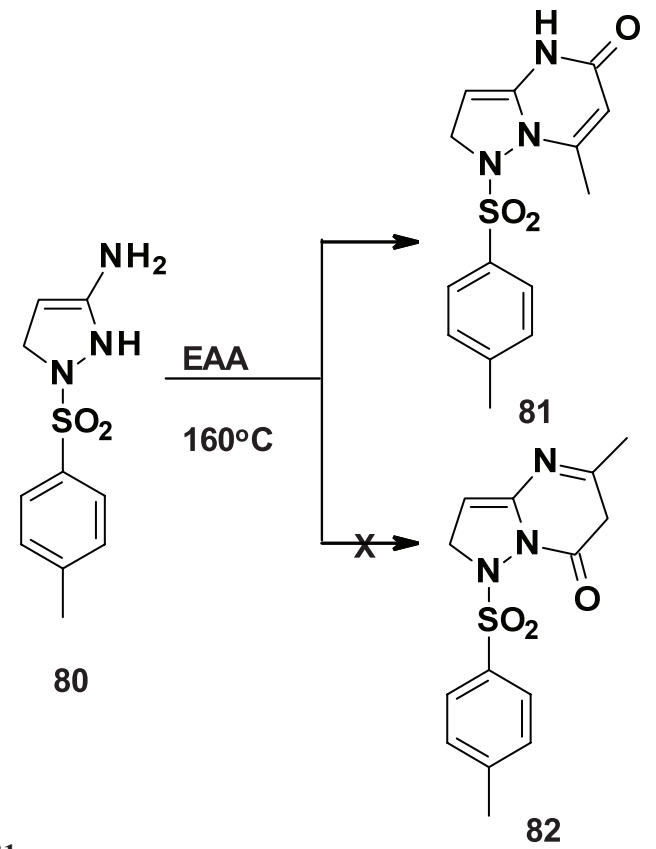

Scheme 31 .

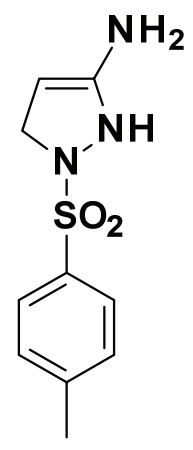

80

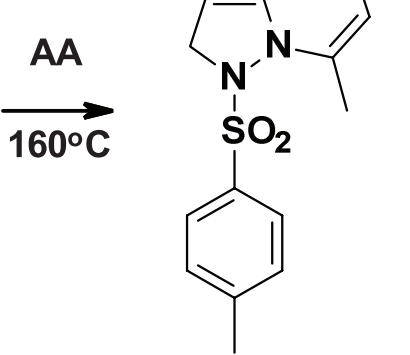

83 4,4-dimethoxybutan-2-one, under different reaction conditions. Heating the reactants in ethanol under reflux for 30' afforded mainly the 5-methylpyrazolo[1,5-a]pyrimidine derivatives $78_{\mathrm{a}, \mathrm{b}}$ and traces of the regio-isomer 7-methyl analog $79_{a, b}$. In contrast, when the reaction was carried out in refluxing ethanol containing a few drops of conc. $\mathrm{HCl}$, the 7-methyl regio-isomers 79 were obtained as the major products together with traces of the 5 -methyl regio-isomer were critically assigned by means of ${ }^{1} \mathrm{H}-{ }^{13} \mathrm{C}$ $2 \mathrm{D}$ experiments and gated decoupled spectra from which onebond and long-range ${ }^{13} \mathrm{C}-{ }^{1} \mathrm{H}$ coupling constants were determined (Scheme 30).

Inconsistent with what has been reported by Elnagdi (1983), the reaction behavior of 5-aminopyrazoles with $\beta$-ketoesters, Girges et al. (1993) reported that fusion of equimolar amounts of the p-tosylaminopyrazole derivative (80) and EAA at $160^{\circ} \mathrm{C}$ yielded 7-methyl-1,2,4,5-tetrahydro-1-( $p$-tosyl)pyrazolo[1,5-a] pyrimidin-5-one (81) rather than its 5-methyl (regio-isomer) 82 (Scheme 31) based on insufficient spectral information. The reaction of (80) with acetylacetone under the same conditions afforded the corresponding 5,7-dimethyl(pyrazolo[1,5-a] pyrimidine) derivative (83) (Scheme 32).

Makarov et al. (1998) reported that the reaction of 3,5-diaminopyrazole (84) with ethyl $\beta$-chloroacetoacetate (85), 2,4-dichloro-5-nitro-benzoyl acetate (86), and 2-(3,4,5-trimethoxybenzoyl)cyclohexanone (87), in methanolic $\mathrm{HCl}$ gave the corresponding pyrazolo[1,5-a]pyrimidine derivatives 88,89 , and $90_{\mathrm{a}, \mathrm{b}}$, respectively (Scheme 33).

According to the authors, the first step in the reaction of 84 with $\beta$-ketoesters involves a nucleophilic attack by the exocyclic $\mathrm{NH}_{2}$ group followed by subsequent cyclization by the second nucleophilic attack caused by the endocyclic $\mathrm{NH}$ on the ester carbonyl. The reaction of 84 with the 1,3-diketone 87 may proceed through two pathways to afford, potentially, tricyclic products 90 and $90,{ }^{1} \mathrm{H}-\mathrm{NMR}$ spectra indicate a single product rather than a mixture of two products. Structure $90_{\mathrm{b}}$ was ruled out on the ground of evidence-based structural assignment of substituents on 90 by X-ray diffraction analysis (Fig. 4).

Scheme 32 .

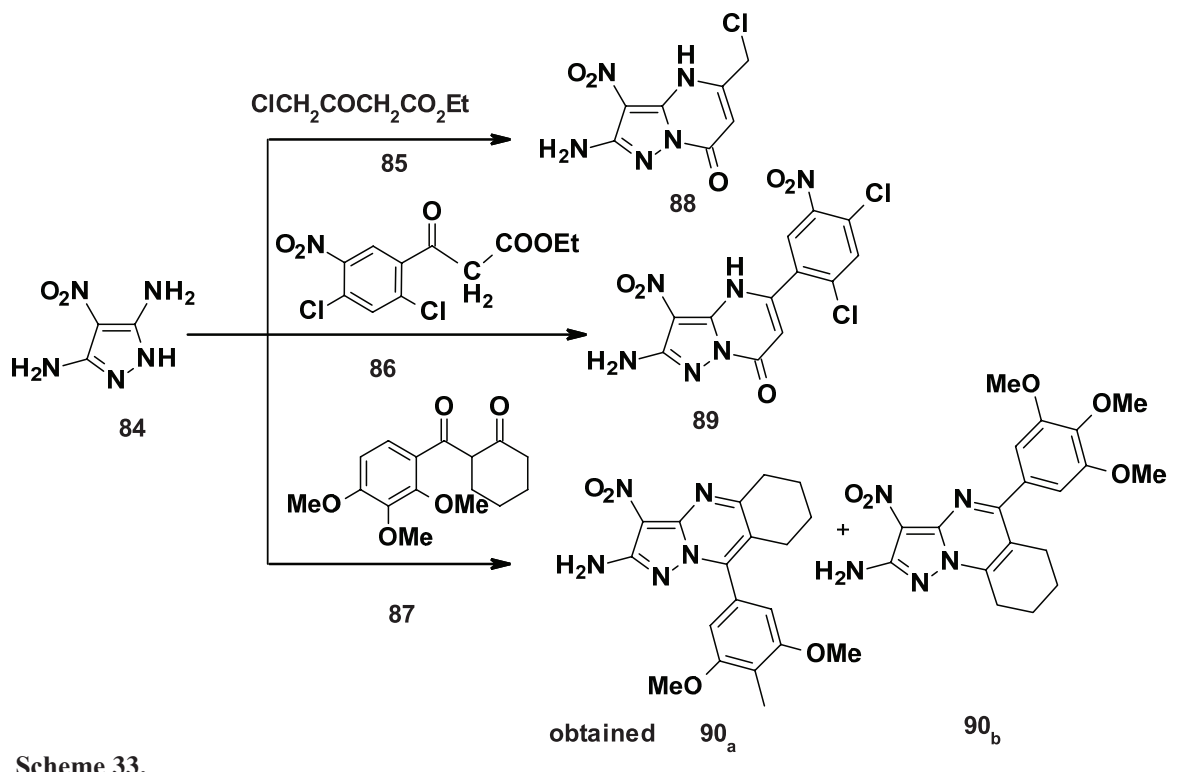

Scheme 33. 


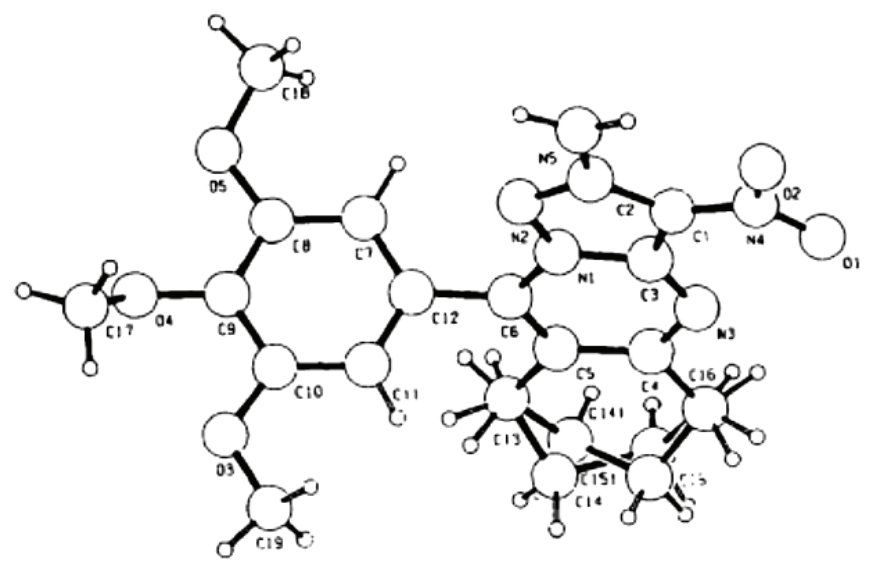

Figure 4. X-ray diffractional analysis of compound 90a. Makarov et al. (1998).

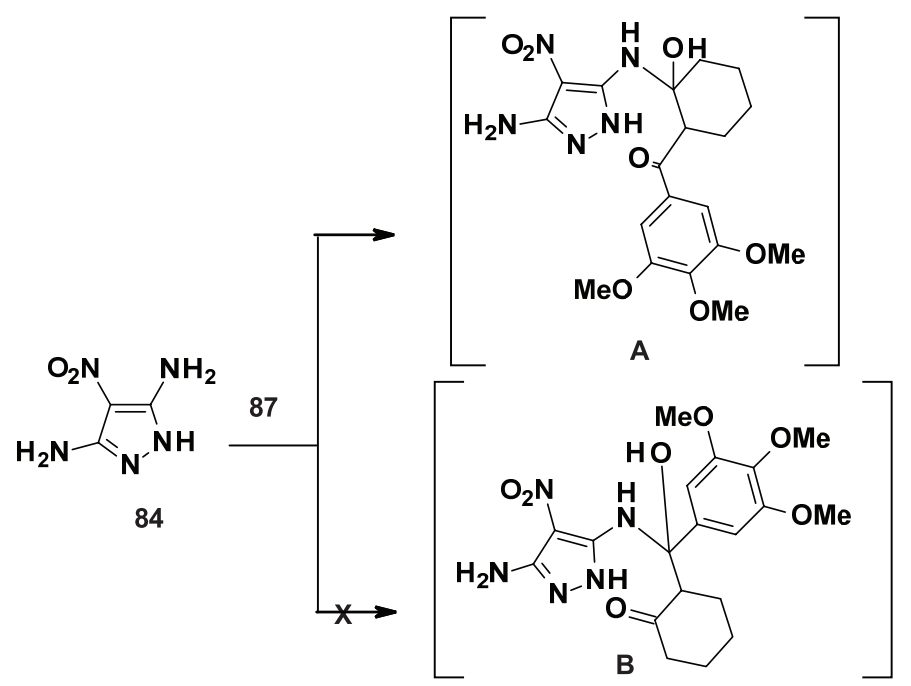

Scheme 34 .

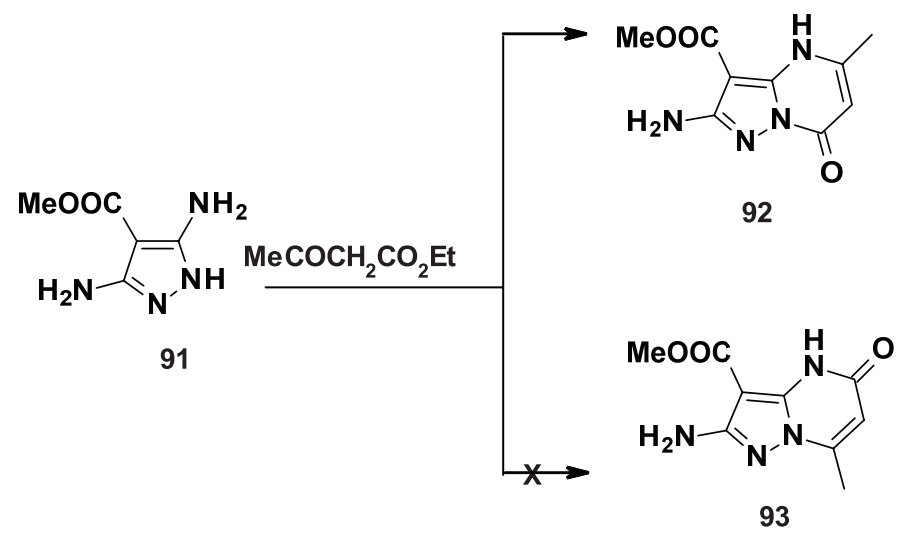

Scheme 35.

Noteworthy, the authors proposed the formation of intermediates A and B from the reaction of 84 with 87 assumed that intermediate $\mathrm{A}$ is energetically more favorable due to the conjugation of the carbonyl with the phenyl $\pi$-bond (Scheme 34 ).

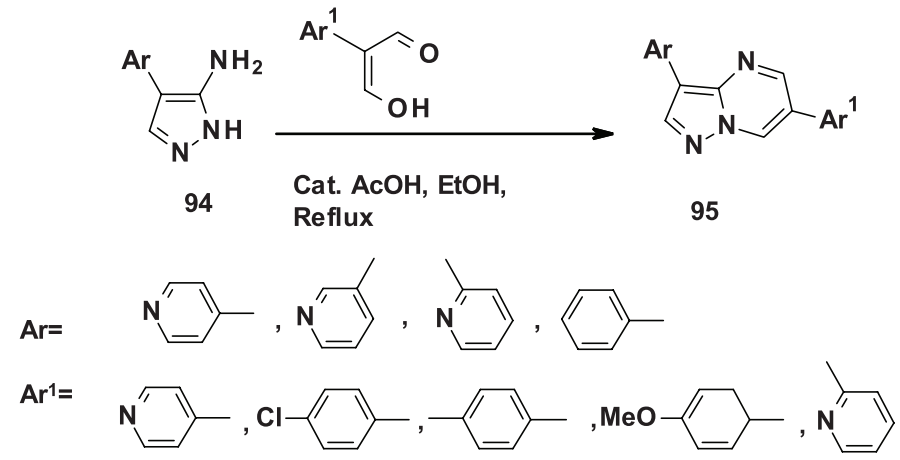

Scheme 36.

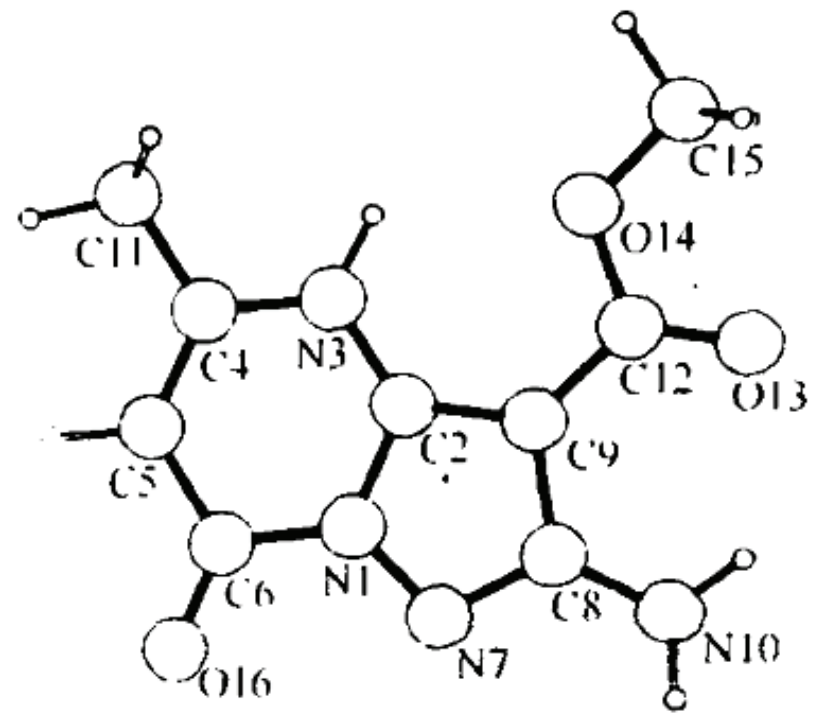

Figure 5. X-ray numbering of atoms and structure of compound 92 (Makarov et al., 2000).

Makarov et al. (2000) reported that the reaction of 4-methoxycarbonyl-3,5-diaminopyrazole (91) with acetoacetic ester gave the corresponding 7-oxopyrazolo[1,5-a]pyrimidine analogue (92) rather than the regio-isomer 5-oxo pyrazolo[1,5-a] pyrimidine (93). This result is consistent with what has been reported by Makarov et al. (1998), concerning the reaction of 4-nitro-3,5-diaminopyrazole with acetoacetic ester while contradicts the results reported by Elnagdi et al. (1983). The structure of the regio-isomer 7-oxo pyrazolo[1,5-a]pyrimidine derivative 92 was confirmed by isotopic exchange experiment $(\mathrm{NH}$ for ND) in their ${ }^{13} \mathrm{C}$ NMR spectra and X-ray diffraction analysis -

Fraley et al. (2002) prepared in combinatorial fashion a set of 3,6-dichloro pyrazolo[1,5-a]pyrimidine 95 through a condensation reaction of a 3-amino-4-arylpyrazole 94 with 2-aryl malonaldehydes in ethanol containing a catalytic amount of acetic acid (Scheme 36).

In this article (Fraley et al., 2002), a convenient method for varying the substituents at the 3-position which avoids repetitious 3-aminopyrazole synthesis, involves reaction of 3-amino-4-bromopyrazole (96) with arylmalonoaldehydes to afford the corresponding 3-bromo-6-arylpyrazolo[1,5-a] pyrimidine $97_{\mathrm{ab}}$, which smoothly cross-coupled with arylboronic 


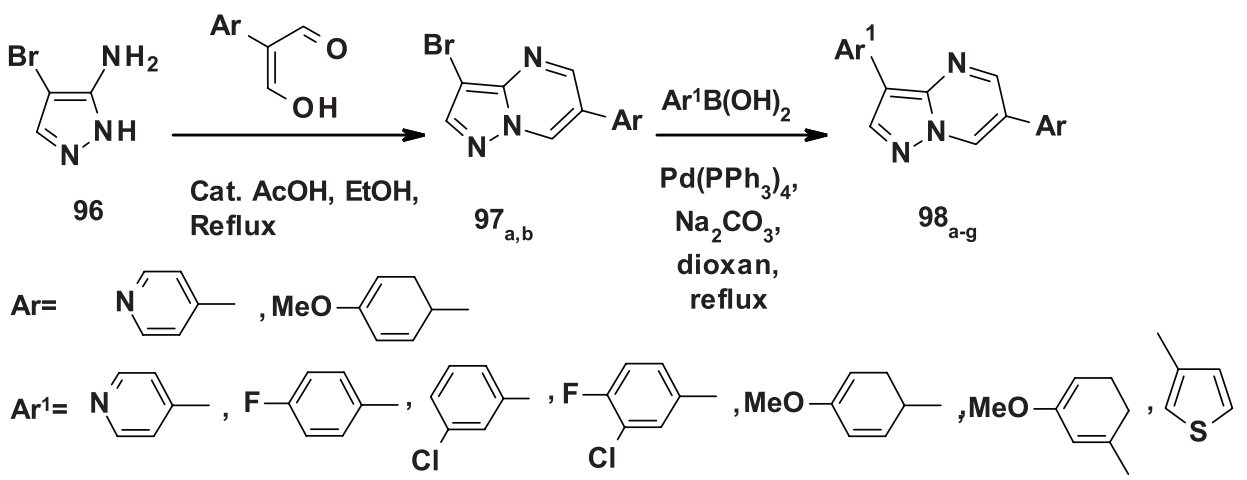

Scheme 37.
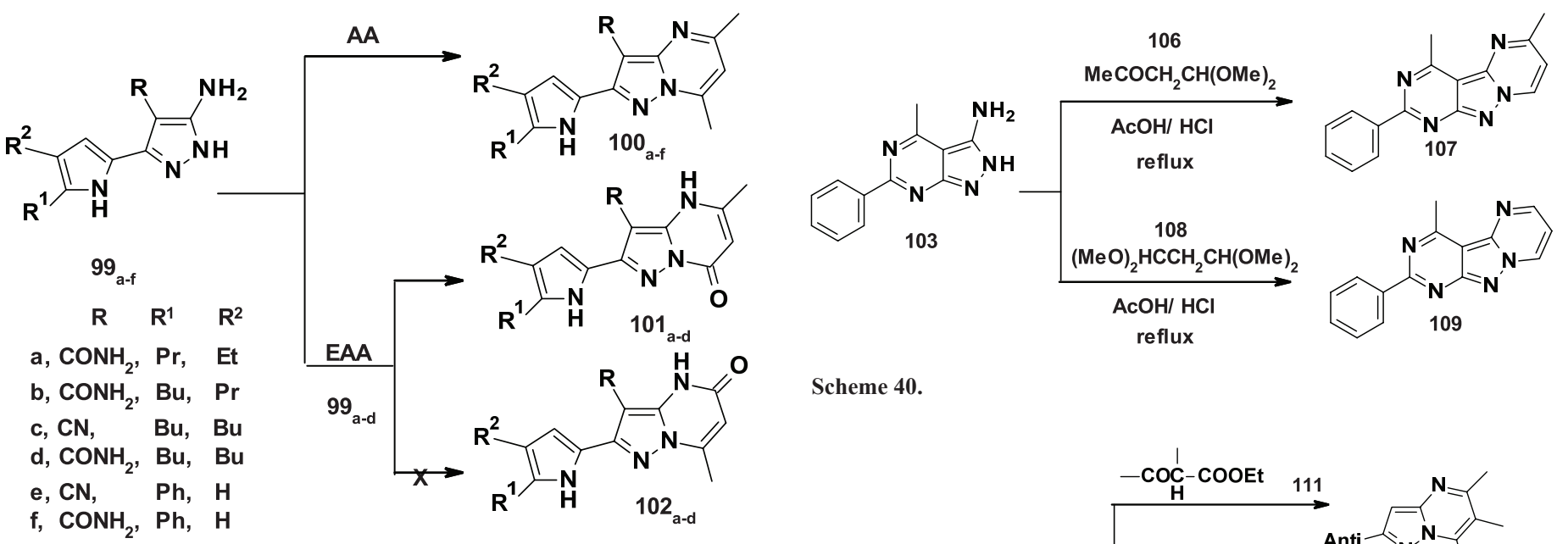

Scheme 40.

Scheme 38 .
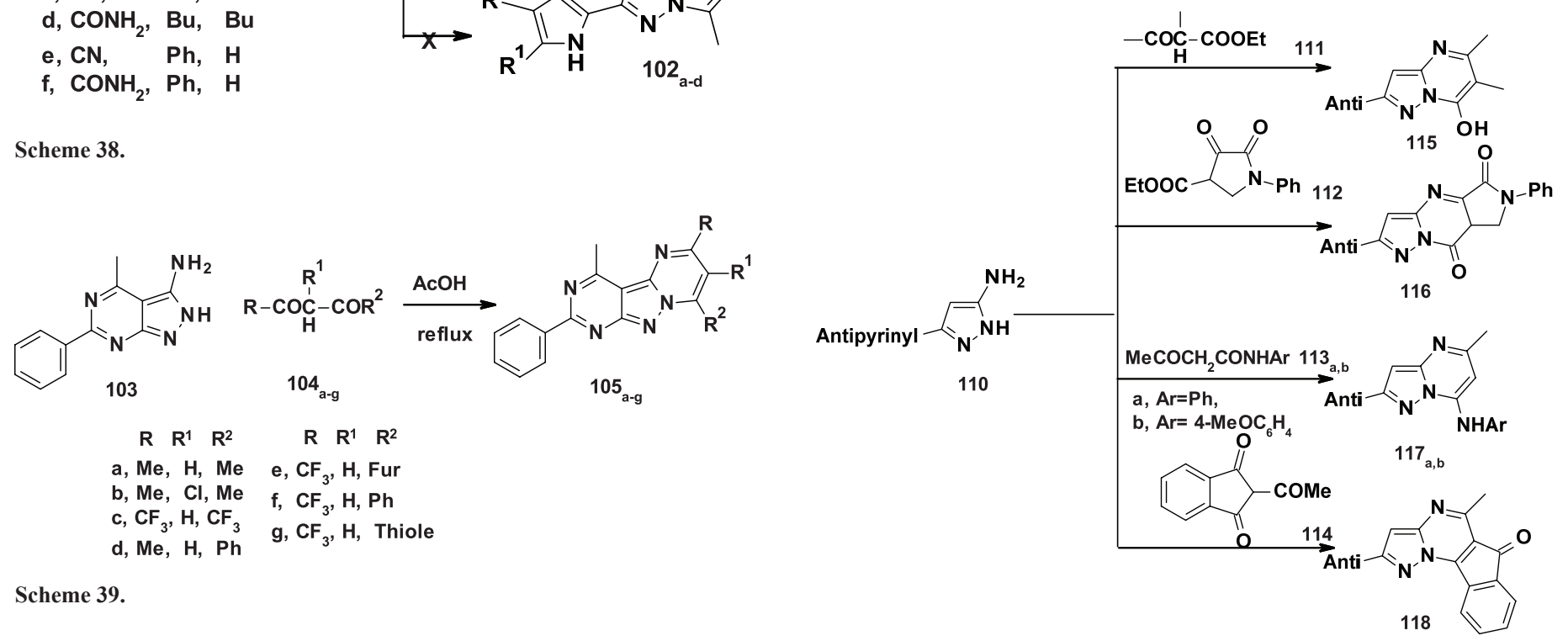

Scheme 39.

Scheme 41.

acids under Suzuki conditions to afford 3,6-diaryl pyrazolo[1,5-a] pyrimidines $98_{\mathrm{a}-\mathrm{g}}$ in fair yields (Scheme 37 ).

Petrova et al. (2003) reported that the condensation of 5-amino-3-(2-pyrrolyl)pyrazoles $99_{\text {a-f }}$ with acetylacetone and ethyl acetoacetate under different reaction conditions resulted in the formation of the corresponding pyrazolo[1,5-a]pyrimidine $100_{\mathrm{a}-\mathrm{f}}$ and $101_{\mathrm{a}-\mathrm{d}}$, respectively (Scheme 38). In the case of EAA, the formation of the regio-isomer $101_{\mathrm{a}-\mathrm{d}}$ was selectively obtained rather than the regio-isomer $102_{\mathrm{a}-\mathrm{d}}$.
Noteworthy, the authors criticized the method reported by Danagulyan et al. (2002) for the preparation of 100e, under the given conditions (ethanol containing a catalytic amount of $\mathrm{AcOH}$ 1 hour at room temperature).

Ho and Yao (2003) reported that the pyrazolopyrimidine 103 reacted with different 1,3 -diketones $104_{\mathrm{a}-\mathrm{g}}$, in refluxing acetic acid to afford the corresponding pyrimido pyrazolo[1,5-a] pyrimidines $105_{\mathrm{a}-\mathrm{g}}$ (Scheme 39). According to the authors, the 


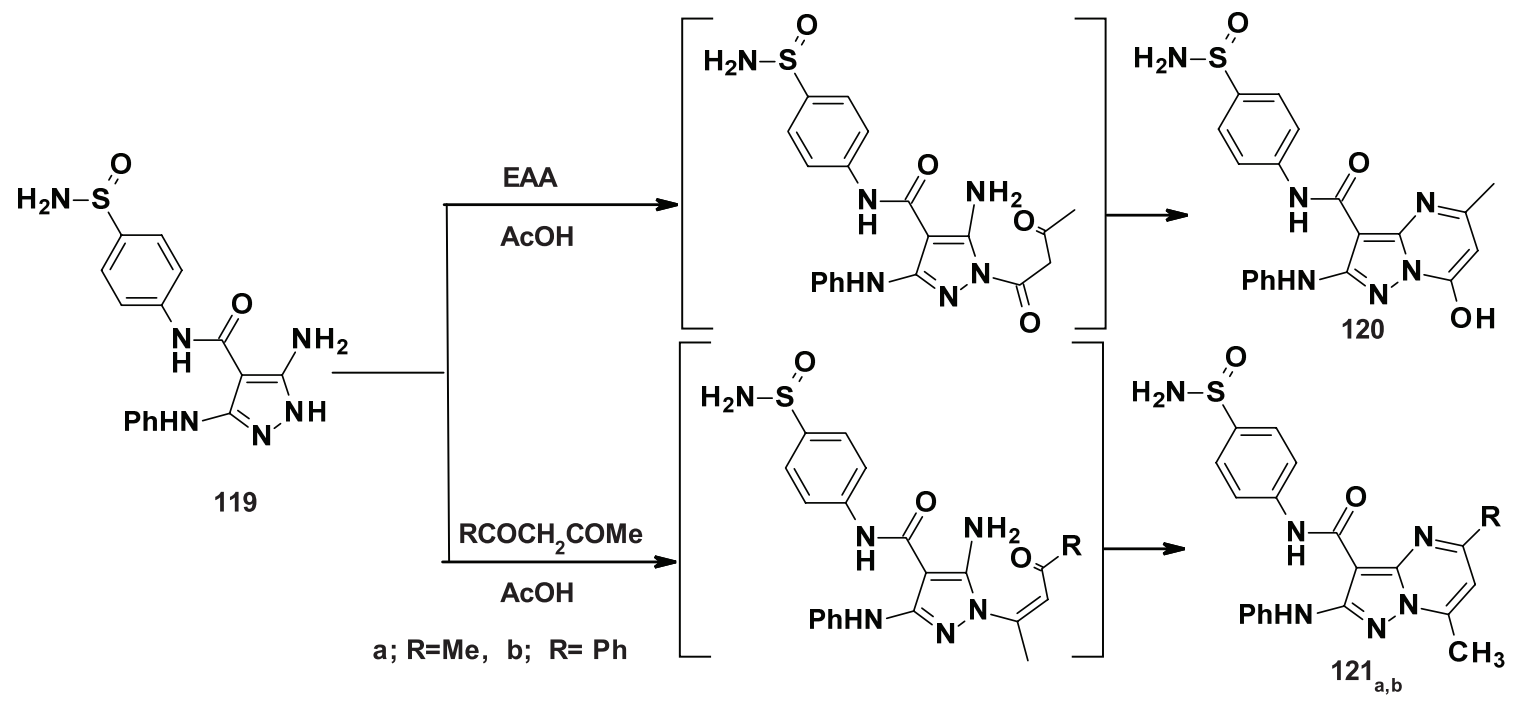

Scheme 42.

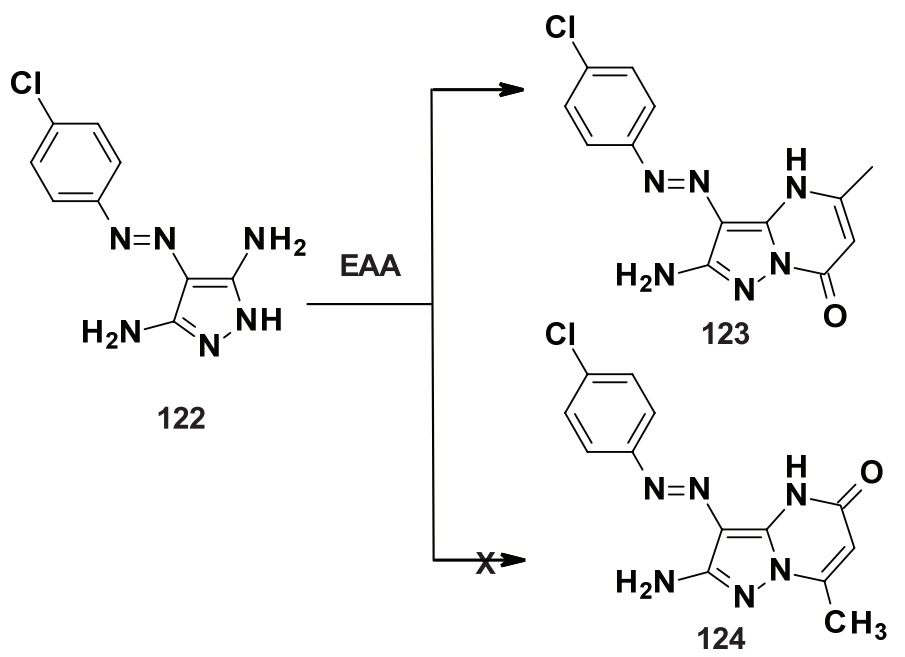

Scheme 43.

reaction probably involves the condensation of the 3-amino group of the pyrazolo[3,4-d]pyrimidine with the carbonyl group followed by dehydration and subsequent cyclization with loss of water.

Condensation of 103 with 4,4-dimethoxy-2-butanone (106) in refluxing $\mathrm{AcOH} / \mathrm{HCl}$ afforded 4,6-dimethyl-2phenylprimido[2,3:4,3] pyrazolo[1,5-a]pyrimidine (107). Also, reaction of 103 with malonaldehyde-bis(dimethylacetal) (108) in $\mathrm{EtOH} / \mathrm{HCl}$ gave 4-methyl-2-phenylpyrimido-pyrazolo[1,5-a] pyrimidine derivative (109) (Scheme 40).

Elmaaty and El-Taweel (2003) reported that 5-amino-2antipyrinylpyrazole 110 reacted with ethyl $\alpha$-methyl acetoacetate $111, \beta$-ketoester 112 , $\beta$-ketoamide $113_{\mathrm{a}, \mathrm{b}}$, and 2 -acetyl indan-1,3dione (114), under different reaction to afford the corresponding pyrazolo[1,5-a]pyrimidines $115,116,117 \mathrm{a}, \mathrm{b}$, and 118 . Formation of such pyrazolo[1,5-a]pyrimidines was assumed to proceed via initial nucleophilic attack by the exocyclic $\mathrm{NH}_{2}$ group of pyrazole on the ketonic function followed by cyclization with the elimination of ethanol or $\mathrm{H}_{2} \mathrm{O}$ (Scheme 41). The same reaction pathway and mechanism were confirmed by other authors (Gregg et al., 2007).
Ammar et al. (2009) reported that the reaction of 3(5)-aminopyrazole 119 with EAA, acetylacetone, and benzoylacetone gave the respective pyrazolo[1,5-a]pyrimidines $120,121_{a, b}$. The authors believed the relative higher nucleophilicity of the endocyclic NH group of the pyrazole ring based only on what they previously reported (Ammar et al., 1995; Zaharan et al., 2001) (Scheme 42).

Al-Zaydi (2009b) unambiguously assigned the structure of 3,5-diaminopyrazole 122 with EAA as 5-methylpyrazolo[1,5-a]pyrimidin-7-one derivative 123 rather than the regio-isomer 124 based on X-ray crystallographic data (Scheme 43).

In 2012, regioselectivity of the reaction between nine different 3(5)-aminopyrazoles $125_{\text {a-i }}$ and 2-acetylcyclohexanone 126, 127 has been investigated (Petrov et al., 2012), under different conditions. The corresponding cycloalkane[e]pyrazolo[1,5-a] pyrimidines $128_{\mathrm{a}-\mathrm{i}}, \quad 129_{\mathrm{b}-\mathrm{i}}$ and cycloalkane[d]pyrazolo[1,5-a] pyrimidines $130_{a-h}, 131_{a-h}$ were obtained. The regio-structure of the compounds was established by ${ }^{1} \mathrm{H}$ and ${ }^{13} \mathrm{C}$ NMR spectroscopy (Scheme 44). 

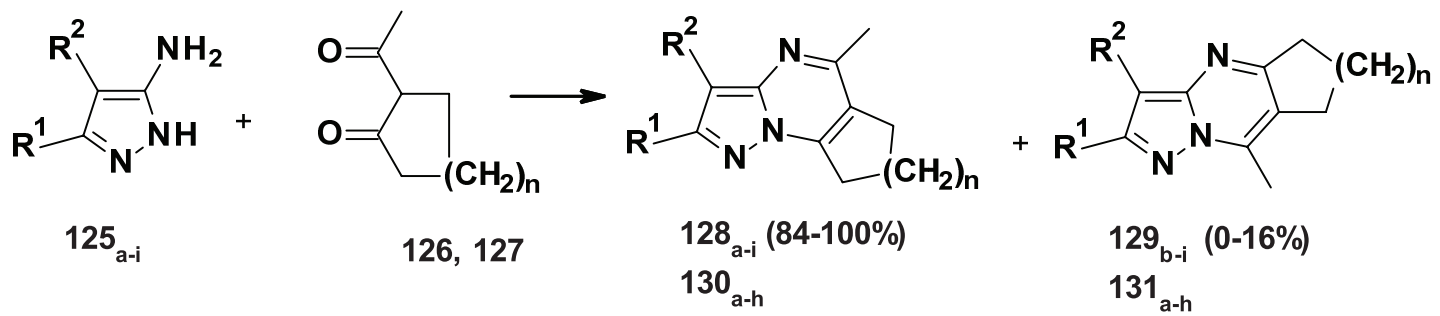
a, $R^{1}=\mathrm{Me}, \mathrm{R}^{2}=\mathrm{H}$;
b, $R^{1}=4-M_{e} C_{6} H_{4}, R_{2}=H$
c, $\mathbf{R}^{1}=\mathrm{H}, \mathbf{R}^{2}=\mathrm{CN}$;
d, $R^{1}=H$,
$\mathrm{R}^{2}=\mathrm{C}_{6} \mathrm{H}_{5}$
e, $R^{1}=H, R^{2}=4-C l-C_{6} H_{4}$,
f, $\mathbf{R}^{1}=\mathrm{H}$,
$\mathrm{R}^{2}=4-\mathrm{MeO}^{2}-\mathrm{C}_{6} \mathrm{H}_{4}$
g, $R^{1}=\mathrm{Me}, \mathrm{R}^{2}=\mathrm{Ph}$,
$h, R 1=M e$,
$\mathrm{R}^{2}=4-\mathrm{MeOC}_{6} \mathrm{H}_{4}$
i, $R^{1}=\mathrm{Me}, \mathrm{R}^{2}=2-\mathrm{MeOC}_{6} \mathrm{H}_{4}$
$n=1(126,128,130), 2(127,129,131)$

Scheme 44.
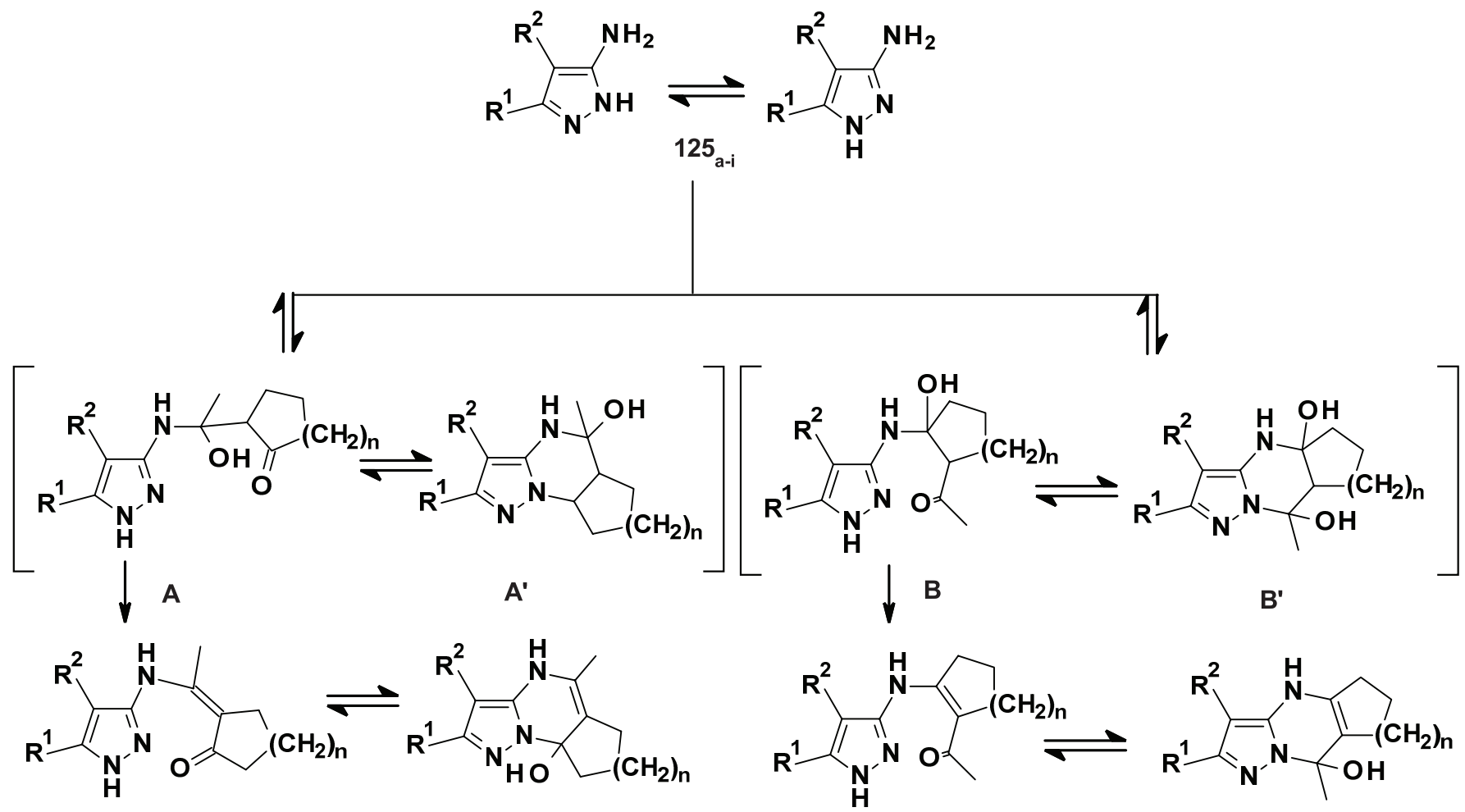
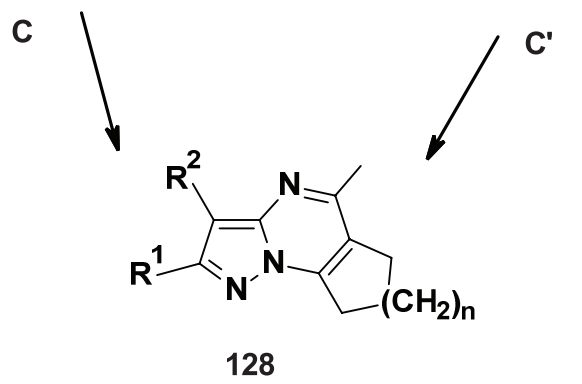

128

130
$C^{\prime}$

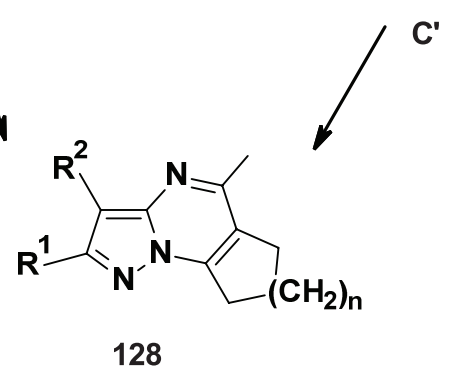

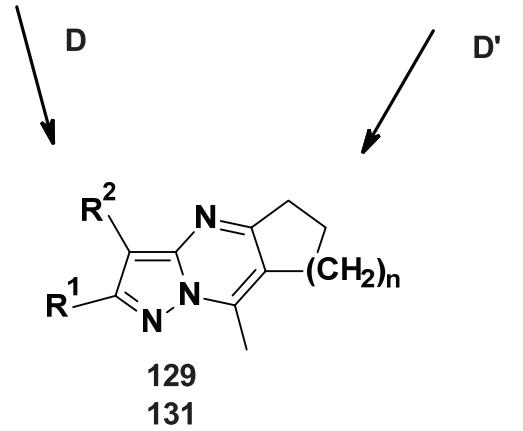




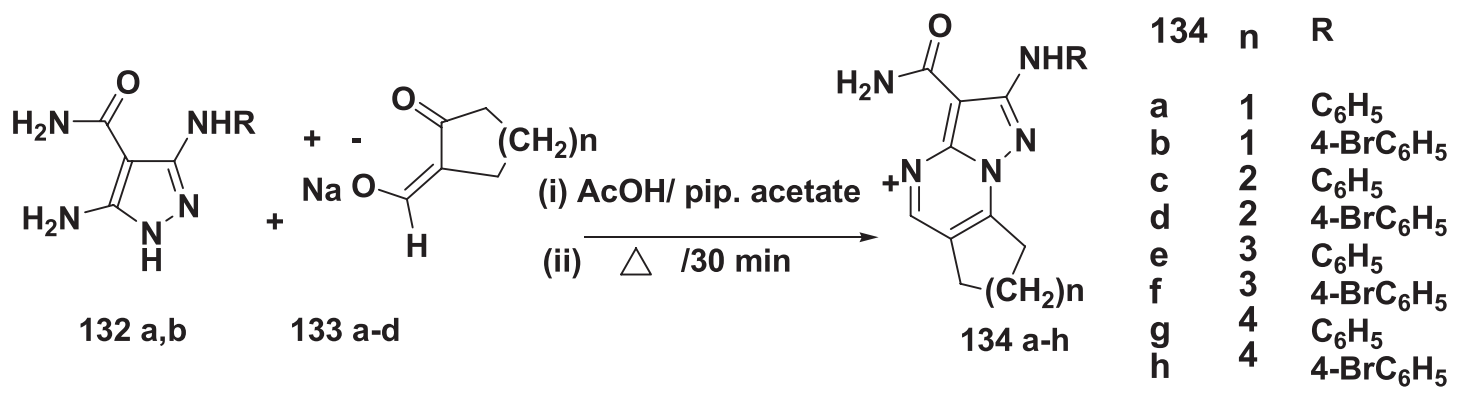

\section{a, $\mathrm{R}=\mathrm{C}_{6} \mathrm{H}_{5}$ \\ b, $\mathrm{R}=4-\mathrm{BrC}_{6} \mathrm{H}_{5}$}

$a, n=1 ; b, n=2 ; c, n=3 ; d, n=4$

Scheme 46.
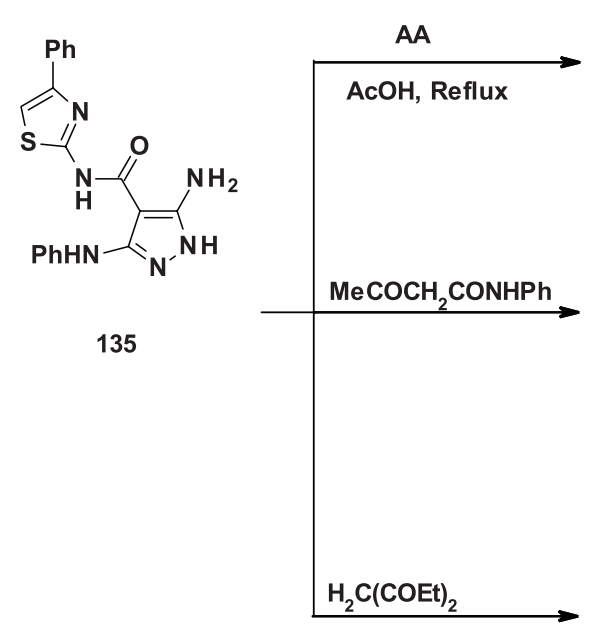

Scheme 47.

The reaction sequence involves the nucleophilic addition of the exocyclic $\mathrm{NH}_{2}$ group of the pyrazole on the acetyl carbonyl or the ring carbonyl of the 1,3-dicarbonyl reagent forming intermediates $\mathrm{A}\left(\mathrm{A}^{\prime}\right)$ or $\mathrm{B}\left(\mathrm{B}^{\prime}\right)$. Then in succession two molecules of water were eliminated with the formation of the final products 128-131. The presence of intermediates C (and or C') alongside with products $128_{\mathrm{d}}, 129_{\mathrm{d}}$ was detected by high-resolution mass spectroscopy: in a solution, in DMSO, of a mixture of aminopyrazole $125_{\mathrm{d}}$ and 2-acetylcyclopentanone 126 after 3 days masses $[\mathrm{M}+\mathrm{H}]^{+} 250.1339$ and 268.1446 (Scheme 45).

7,8-dihydro-6H-cycloalkan [e]pyrazolo[ 1,5 -a ] pyrimidine-3-carboxamide derivatives $134 \mathrm{a}-\mathrm{h}$ were prepared (Abdallah and Elgemeie, 2018) by reacting aminopyrazoles 132a,b with the sodium salt of (hydroxymethylene)-cycloalkanones 133a$\mathrm{d}$ and piperidine acetate. The reaction mixture was heated and was in the water for $25 \mathrm{~min}$, and then acetic acid was added in the middle of the reaction time (Scheme 46).<smiles>[R]COC(=O)CC([X])C(=O)OCC</smiles>

a, $X=M e$,

b, $\mathrm{X}=\mathrm{CH}_{2}$ COOEt

Scheme 48.

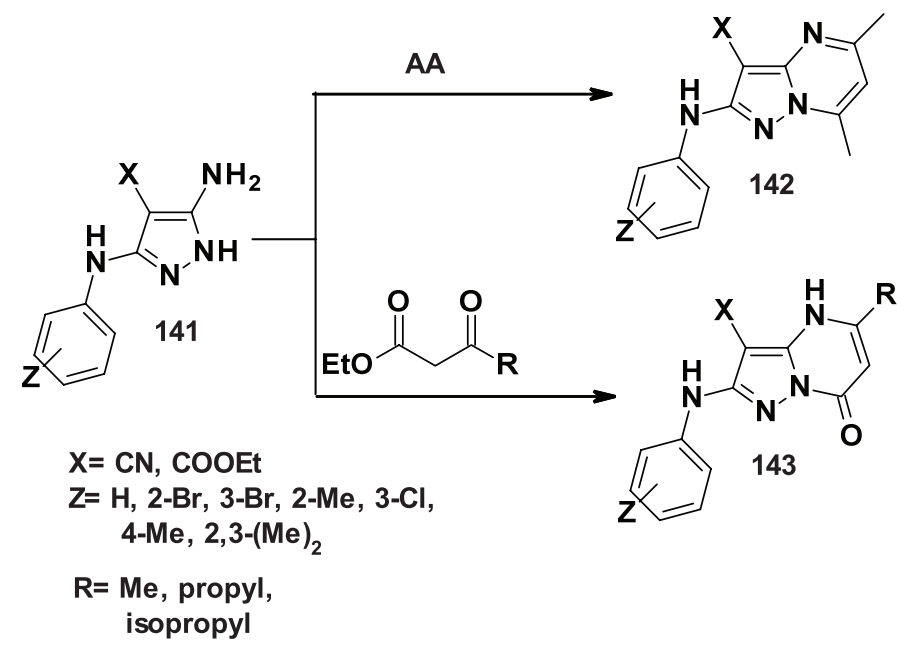

Scheme 49.

Bondock et al. (2015) reported that condensation of 3(5)-aminopyrazole derivative 135 with acetylacetone, in boiling AcOH, gave the corresponding pyrazolo[1,5-a]pyrimidine 136 . Similarly, the reaction of 135 with acetoacetamide afforded the regio-isomer pyrazolo[1,5-a]pyrimidine 137 based on what has been reported by Kleschick in 1989. They assumed that the initial nucleophilic attack induced by the exocyclic $\mathrm{NH}_{2}$ group of pyrazole on the ketonic carbonyl of acetoacetanilide, followed by cyclization via nucleophilic substitution on the amide carbonyl by the endocyclic $\mathrm{NH}$ of the pyrazole and loss of the aniline molecule. The solvent-free reaction of 135 with diethyl malonate at $160^{\circ} \mathrm{C}$, afforded the corresponding 5,7-dihydroxy pyrazolo[1,5-a] pyrimidine 138 (Scheme 47). 

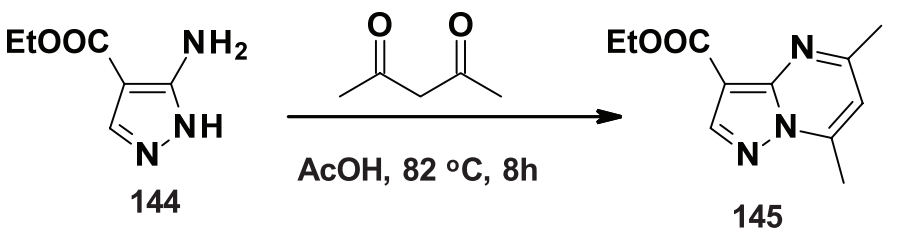

Scheme 50.

Abbas-Temirek and Abo-Bakr (2016) reported that the reaction of 3(5)-aminopyrazole 139 with EAA and diethyl3-oxoglutarate produced the corresponding pyrazolo[1,5-a] pyrimidines $140_{\mathrm{a}, \mathrm{b}}$. Regio-orientation was not discussed and the structures of the products were supported by ${ }^{1} \mathrm{H}$ and ${ }^{13} \mathrm{C}$ NMR (not reliable without deep investigation) in addition to what has been previously reported by Elnagdi et al. (1993) (Scheme 48).

Marjani et al. (2015) reported the synthesis of pyrazolo[1,5-a]pyrimidine analogs 142,143 via condensation of substituted 3(5)-aminopyrazoles 141, independently, with acetylacetone and certain ketoesters in the presence of $\mathrm{H}_{2} \mathrm{SO}_{4}$ using $\mathrm{AcOH}$ as solvent (Scheme 49).

According to the authors, the reaction mechanism involves an initial nucleophilic attack by the exocyclic $\mathrm{NH}_{2}$ group on the ketonic function followed by subsequent cyclization. Although the regioselectivity of the reaction was not discussed, the structures of the products were confirmed by ${ }^{1} \mathrm{H}$ NMR, ${ }^{13} \mathrm{C}$ NMR, FT-IR, and elemental analysis.

5,7-dimethylpyrazolo[1,5-a]pyrimidine carboxylic acid 145 was synthesized (Kumar et al., 2016) by heating ethyl 3(5)-aminopyrazole-4-carboxylate (144) with acetylacetone in the acetic acid medium at $82^{\circ} \mathrm{C}$, in good yield (Scheme 50 ).

\section{ABBREVIATIONS}

AcOH: acetic acid, DMSO: dimethylsulfoxide, EAA: ethyl acetoacetate, ECA: ethyl cyanoacetate, $\mathrm{EtOH}$ : ethanol, $\mathrm{HCl}$ : hydrochloric acid, WB: water bath.

\section{CONFLICT OF INTEREST}

The authors declare no conflict of interest. The authors alone are responsible for the content and writing of this article.

\section{REFERENCES}

Abbas-Temirek HH, Abo-Bakr AM. Reactions with heterocyclic amidines: synthesis of several new pyrazolo $[1,5-\mathrm{a}]$ pyrimidines and pyrazolo [1, 5-a][1, 3, 5] triazines. Eur J Chem, 2016; 7(1):107-14.

Abdallah AEM, Elgemeie GH. Design, synthesis, docking, and antimicrobial evaluation of some novel pyrazolo[1,5-a] pyrimidines and their corresponding cycloalkane ring-fused derivatives as purine analogs. Drug Des Devel Ther, 2018; 12:1785-98.

Al-Omran F, El-Khair AA. 2-(3-Arylhydrazono-3-formyl-2oxopropyl)-1H-isoindole-1, 3 (2H)-dione in heterocyclic synthesis. Novel derivatives of pyridazin-6 $(1 \mathrm{H})$-one, pyridazin- $6(1 \mathrm{H})$-imine, and pyrazolo $[5,1-c][1,2,4]$ triazine incorporating an $\mathrm{N}$-(2-oxoethyl) phthalimide moiety. J Chem Res, 2006; 2006(1):6.

Al-Shiekh MA, El-Din AMS, Hafez EA, Elnagdi MH. $\beta$-Enones in heterocyclic synthesis, Part I. Classical synthetic and environmentally friendly synthetic approaches to alkyl and acyl azoles and azines. J Chem Res, 2004; 2004(3):174.

Al-Zaydi KM. Synthesis of fused pyrazolo (1, 5-a) pyrimidine derivatives under microwave irradiation and ultrasound, as ecofriendly energy sources. Heterocycles, 2009a; 78(8):2003.
Al-Zaydi KM. A simplified green chemistry approaches to synthesis of 2-substituted 1,2,3-triazoles and 4-amino-5-cyanopyrazole derivatives conventional heating versus microwave and ultrasound as ecofriendly energy sources. Ultrason Sonochem, 2009b; 16(6):805-9.

Ammar Y, EL-Sharief AS, Zahran M, El-Said M, EL-Said U. Studies on activated nitriles: synthesis of new 3-Cyano-2-(3-tolylamino) pyrazolo (1, 5-a) pyrimidines. ChemInform, 1995; 26(49).

Ammar YA, Aly MM, Al-Sehemi AAG, Salem MA, El-Gaby MS. Cyanoacetanilides intermediates in heterocyclic synthesis. Part 5: preparation of hitherto unknown 5-aminopyrazole and pyrazolo [1, 5-a] pyrimidine derivatives containing sulfamoyl moiety. J Chin Chem Soc, 2009; 56(5):1064-71.

Ancoli-Israel S, Walsh JK, Mangano RM, Fujimori M, Group ZCS. Zaleplon, a novel nonbenzodiazepine hypnotic, effectively treats insomnia in elderly patients without causing rebound effects. Prim Care Companion J Clin Psychiatry, 1999; 1(4):114.

Bagley MC, Davis T, Dix MC, Widdowson CS, Kipling D. Microwave-assisted synthesis of $\mathrm{N}$-pyrazole ureas and the p38 $\alpha$ inhibitor BIRB 796 for study into accelerated cell ageing. Organ Biomol Chem, 2006; 4(22):4158-64.

Bajwa JS, Sykes PJ. Synthesis and structure of some azolo [a] pyrimidines, 2, 6, 7, 8-tetrahydro-1 $\mathrm{H}$-cyclopenta [e] azolo [a] pyrimidines, 6, 7-dihydro-5 H-cyclopenta [f] azolo [a] pyrimidines, 7, 8-dihydro-6 H-cyclopenta [f]-s-triazolo [4, 3-b] pyridazine, 5, 6, 7, 8-tetrahydro-azolo [b] quinazolines, 6, 7, 8, 9-tetrahydroazolo [a] quinazolines, and 7, 8, 9, 10-tetrahydro-s-triazolo [3, 4-a] phthalazine. J Chem Soc, Perkin Transact 1, 1979:3085-94.

Banister SD, Wilkinson SM, Hanani R, Reynolds AJ, Hibbs DE, Kassiou M. A practical, multigram synthesis of the 2-(2-(4-alkoxyphenyl)5,7-dimethylpyrazolo[1,5-a]pyrimidin-3-yl)acetamide (DPA) class of high affinity translocator protein (TSPO) ligands. Tetrahedron Lett, 2012/07/18/ 2012; 53(29):3780-3.

Barfield M, Chakrabarti B. Long-range proton spin-spin coupling. Chem Rev, 1969; 69(6):757-78.

Bondock S, Tarhoni AEG, Fadda AA. Regioselective synthesis of some new pyrazolo $[1,5-\mathrm{a}]$ pyrimidines, pyrazolo $[1,5-\mathrm{a}]$ quinazoline and pyrimido $\left[4^{\prime}, 5^{\prime}: 3,4\right]$ pyrazolo $[1,5$-a] pyrimidines containing thiazole moiety. J Heterocycl Chem, 2015; 52(6):1792-9.

Chan KK-L, Leung TH-Y, Chan DW, Wei N, Lau GT-Y, Liu SS, Siu MK, Ngan HY-S. Targeting estrogen receptor subtypes (ER $\alpha$ and ER $\beta$ ) with selective ER modulators in ovarian cancer. J Endocrinol, 2014; 221(2):325-36.

Chilman-Blair K, Castaner J, Silvestre J. Ocinaplon: treatment of generalized anxiety disorder GABAAreceptor modulator. Drugs Future, 2003; 28(2):115-20.

Chimichi S, Cosimelli B, Bruni F, Selleri S. 1H and 13C NMR study of the pyrazolo [1, 5-a] pyrimidine system. Canad J Chem, 1992; 70(4):1093-7.

d'Aniello F, Santos B, Guglietta A. Lorediplon: a new GABA A modulator drug for treatment of insomnia. In: Drug Treatment of Sleep Disorders, Springer, pp 121-45, 2015.

Danagulyan G, Panosyan G, Boyakhchyan A. Synthesis of n-alkylated derivatives of pyrazolo [1,5-a] pyrimidine and their reaction with methylamine. Chem Heterocycl Com, 2002; 38(5):581-5.

Dawood KM, Farag AM, Abdel-Aziz HA. Azoles and azoloazines via 3-(3-methylbenzofuran-2-yl)-3-oxopropanenitrile. J Chem Res, $2005 ; 2005(6): 378$.

de Waard MA. Mechanisms of action of the organophosphorus fungicide pyrazophos, Veenman, 1974.

Dymek W, Janik B, Zimoń R. Studies on pyrazole derivatives. II. Acta poloniae pharmaceutica, 1965; 22(3):209-17.

Ege G, Gilbert K. Reactions with diazo-azoles. 2.[7+ 1]-cycloreactions and $(11+1]$-cycloreactions of diazo-azoles with 1-nucleophile-1-electrophiles (ylides) to 3h-pyrazolo $(5,1-c][1,2,4]$ triazoles and $3 \mathrm{~h}-(1,2,4]$ triazolo $(4,3-\mathrm{b}]$ indazoles. Tetrahedron Lett, 1979a; (18):1567-70. 
Ege G, Gilbert K. [7+2]-and [11+2]-cycloaddition reactions of diazo-azoles with isocyanates to azolo $[5,1-d][1,2,3,5]$ tetrazine-4-ones. Tetrahedron Lett, 1979b; 20(44):4253-6.

Ege G, Gilbert K, Heck R. Reaktionen mit Diazoazolen, VII. 3H-Azolo-1, 2, 4-triazole durch 1, 8-bzw. 1, 12-Elektrocyclisierungen von 3H-Pyrazol-3-on-bzw. 3H-Indazol-3-on-(diorganylmethylen) hydrazonen. Chemische Berichte, 1984; 117(5):1726-47.

El-Emary TI, Al-Muaikel N, Moustafa OS. Synthesis and antimicrobial activity of some new heterocycles based on 3-methyl-1phenyl-5-benzene sulfonamido pyrazole. Phosphorus Sulfur, 2002/01/01 2002; 177(1):195-210.

El-Ghandour Ahmed Hafez H, Ibrahim Mohamed Kamal A, Abdel-Hafiz Ibrahim S, Elnagdi Mohamed H. Studies with alkylheteroaromatic carbonitriles: a novel synthesis of pyrazolo[2',3': 3,4$]$ benzo[c]-1,2,4-triazine. Zeitschrift für Naturforschung B, 1992; 47:1628.

El-Mekabaty A, Hasel A. Facile and efficient synthesis of a new class of pyrazolo [1,5-a] pyrimidine derivatives via one-pot multicomponent reactions. Chem Heterocycl Com, 2015; 50(11):1608-15.

Elagamey AGA, El-Taweel F, Amer F. Synthesis of some new pyrazolo $[1,5$-a $]$ pyrimidine and pyrazolo $[1,5$-c]-as-triazine derivatives. Collect Czechoslov Chem Commun, 1986; 51(10):2193-8.

Elmaati TMA, El-Taweel FM. Routes to Pyrazolo [3, 4-e][1, 4] thiazepine, pyrazolo $[1,5-\mathrm{a}]$ pyrimidine and pyrazole derivatives. J Chin Chem Soc, 2003; 50(3A):413-8.

Elnagdi M, Fleita D, El-Moghayar M. Reactions with $\beta$-cyanoethylhydrazine-II: synthesis of some 4, 5, 6, 7-tetrahydropyrazolo [1, 5-a] pyrimidine derivatives. Tetrahedron, 1975a; 31(1):63-7.

Elnagdi M, Kandeel B, Elmoghayar M. Z. Naturforsch, B. Anorg Chem Org Chem, 1977; 32.

Elnagdi MH, Allah SOA. Reactions with the Arylhydrazones of some $\alpha$-cyanoketones. J Prakt Chem, 1973; 315(6):1009-16.

Elnagdi MH, Ohta M. Studies on 3, 5-pyrazolidinediones. IV. Addition of 4-Arylazo-3, 5-pyrazolidinediones to Ethyl Acrylate. Bull Chem Soc Jpn, 1973; 46(6):1830-3.

Elnagdi MH. Reactions with $\beta$-cyanoethylhydrazine - I: a route for the preparation of pyrazolo [1.5-a] pyrimidines and pyrrolo [1.2-b] pyrrazoles. Tetrahedron, 1974; 30(16):2791-6.

Elnagdi MH, Kassab NAL, Fahmy SM, El-All FA. Reactions with 3, 5-pyrazolidinediones. III. Cyanoethylation of some 4-Arylazo derivates of 3, 5-pyrazolidinediones and 3-amino-2-pyrazolin-5-ones. J Prakt Chem, 1974; 316(2):177-84.

Elnagdi MH, Sallam MMM, Ilias MAM. Pyrimidine derivatives and related compounds II: synthesis of some derivatives of pyrimido $\left[1,2: 2^{\prime}, 3^{\prime}\right]$ pyrazolo $[1,5$-a] pyrimidines, a new ring system. Helv Chim Acta, 1975b; 58(7):1944-9.

Elnagdi MH, El-Moghayar MR, Fleita DH, Hafez EA, Fahmy SM. Pyrimidine derivatives and related compounds. 4. A route for the synthesis of pyrazolo [3, 4-e]-as-triazines, pyrazolo [3, 4-d] pyrimidines, and pyrazolo [1, 5-c]-as-triazines. J Organ Chem, 1976; 41(24):3781-4.

Elnagdi MH, Kandeel EM, Zayed EM, Kandil ZES. Pyrimidine derivatives and related compounds. VIII [1]. Routes for the Synthesis of 3,5-Diaminopyrazoles, 2-Aminopyrazolo [1, 5-a] pyrimidines and 5-Aminopyrazolo [1, 5-a] pyrimidines. J Prakt Chem, 1978; 320(4):533-8.

Elnagdi MH, Zayed EM, Khalifa ME, Ghozlan SA. Reactions with heterocyclic amidines, VII: Synthesis of some new pyrazolo [1, 5-c]-1, 2, 4-triazines, pyrazolo [1, 5-a]-1, 3, 5-triazines and pyrazolo [1, 5-a] pyrimidines. Monatshefte für Chemie/Chemical Monthly, 1981; 112(2):245-52.

Elnagdi Mohamed H, Fahmy Sherief M, Elmoghayab Mohamed Riffaat H, Ilias Mohamed Ajmal M. Pyrimidine derivatives and related compounds, I synthesis of some 2,3-disubstituted-4,5,6,7tetrahydropyrazolo[1,5-a]-pyrimidine derivatives. Zeitschrift für Naturforschung B, 1975; 30:778.

Emelina E, Petrov A, Filyukov D. Structure and tautomerism of 4-substituted 3 (5)-aminopyrazoles in solution and in the solid state: NMR study and Ab initio calculations. Russ J Organ Chem, 2014; 50(3): $412-21$.
Ervinna N, Mita T, Yasunari E, Azuma K, Tanaka R, Fujimura S, Sukmawati D, Nomiyama T, Kanazawa A, Kawamori R. Anagliptin, a DPP-4 inhibitor, suppresses proliferation of vascular smooth muscles and monocyte inflammatory reaction and attenuates atherosclerosis in male apo E-deficient mice. Endocrinology, 2013; 154(3):1260-70.

Fraley ME, Hoffman WF, Rubino RS, Hungate RW, Tebben AJ, Rutledge RZ, McFall RC, Huckle WR, Kendall RL, Coll KE. Synthesis and initial SAR studies of 3, 6-disubstituted pyrazolo [1, 5-a] pyrimidines: a new class of KDR kinase inhibitors. Bioorgan Med Chem Lett, 2002; 12(19):2767-70.

Girges M, Hanna M, Fadda A. New heterocyclic bridgehead nitrogen compounds synthesis of 1 -(p-Tosyl) pyrazolo [1, 5-a] pyrimidines and pyrazolo [5, 1-c]-[1, 2, 4]-triazine derivatives. Chem Papers, 1993; 47(3):186-9.

Graubaum H. Acylwanderungen am 3 (5)-Amino-pyrazol. Journal für Praktische Chemie/Chemiker-Zeitung, 1993; 335(7):585-8.

Gregg BT, Tymoshenko DO, Razzano DA, Johnson MR. Pyrazolo [1,5-a] pyrimidines. Identification of the privileged structure and combinatorial synthesis of 3-(hetero) arylpyrazolo [1,5-a] pyrimidine-6carboxamides. J Comb Chem, 2007; 9(3):507-12.

Helal MH, Salem MA, Aly HM. Synthesis, antimicrobial activity and molecular modeling of some novel 5-aminopyrazole, pyrazolo [1, 5-a] pyrimidine, bispyrazole and bispyridone derivatives containing antipyrinyl moiety. J Heterocycl Chem, 2017; 54(5):2614-26.

Ho YW, Yao CT. Synthesis of some new 6, 8-disubstituted 7, 8-dihydropyrimido [2, 3: 4, 3] pyrazolo [1, 5-a] pyrimidines and 6, 7, 8-trisubstituted pyrimido [2, 3: 4, 3] pyrazolo [1, 5-a] pyrimidine derivatives. J Chin Chem Soc, 2003; 50(2):283-96.

Iorga A, Umar S, Ruffenach G, Aryan L, Li J, Sharma S, Motayagheni N, Nadadur RD, Bopassa JC, Eghbali M. Estrogen rescues heart failure through estrogen receptor Beta activation. Biol Sex Differ, 2018; 9(1):48.

Joshi K, Singh P, Singhi C. Chemical constituents of Verbesina encelioides and Holmskioldia sanguinea. J Indian Chem Soc, 1983.

Kandeel EM, Baghos VB, Mohareb IS, Elnagdi MH. Reactions with heterocyclic amidines, XI. Syntheses of new 2-aminopyrazolo [1, 5-a] pyrimidines and 2-amino [1, 5-c]-as-triazines. Archiv Pharmazie, 1983; 316(8):713-8.

Kočevar M, Kolman D, Krajnc H, Polanc S, Porovne B, Stanovnik B, Tišler M. Reactions of some diazoazoles with reactive methylene and other groups. Tetrahedron, 1976; 32(6):725-9.

Kumar A, Bodke Y, Gowda A, Sambasivam G, Bhat K. Design, synthesis, and evaluation of the anticancer properties of a novel series of imidazolone fused pyrazolo[1,5-a]pyrimidine derivatives. J Heterocycl Chem, 2016; 54(3):1904-24.

Lynch BM, Khan MA, Sharma SC, Teo HC. Pyrazolo [1, 5-a] pyrimidine: synthesis and regiospecific electrophilic substitution in the pyrazole and/or pyrimidine rings. Canad J Chem, 1975; 53(1):119-24.

Makarov V, Tafeenko V, Granik V. Synthesis of pyrazolo [1, 5-a] pyrimidines by the reaction of $\beta$-dicarbonyl compounds with 3, 5-diamino4-nitropyrazole. Chem Heterocycl Com, 1998; 34(12):1423-7.

Makarov V, Solov'eva N, Chernyshev V, Sonneveld E, Granik V. Study of the reaction of 3, 5-diamino-4-carbomethoxypyrazole with acetoacetic ester. Synthesis of pyrazolo [1, 5-a] pyrimidine. Chem Heterocycl Com, 2000; 36(1):70-3.

Maquestiau A, Taghret H, Vanden Eynde JJ. Preparation and characterization of pyrazolo [1,5-a] pyrimidines. Bull Soc Chim Belges, 1992; 101(2):131-6.

Marjani AP, Khalafy J, Salami F, Ezzati M. The synthesis of new pyrazolo [1, 5-a] pyrimidine derivatives. Arkivoc, 2015; 277:286.

Michon V, du Penhoat CH, Tombret F, Gillardin J, Lepage F, Berthon L. Preparation, structural analysis and anticonvulsant activity of 3-and 5-aminopyrazole N-benzoyl derivatives. Eur J Med Chem, 1995; 30(2):147-55.

Moyano EL, Colomer JP, Yranzo GI. New Application of heterocyclic diazonium salts: synthesis of new pyrazolo [3, 4-d][1, 2, 3] triazin-4-ones. Eur J Organ Chem, 2008; 2008(19):3377-81. 
Neubauer DN. Indiplon: the development of a new hypnotic. Expert Opin Investig Drugs, 2005; 14(10):1269-76.

Parry D, Guzi T, Shanahan F, Davis N, Prabhavalkar D, Wiswell D, Seghezzi W, Paruch K, Dwyer MP, Doll R. Dinaciclib (SCH 727965), a novel and potent cyclin-dependent kinase inhibitor. Mol Cancer Ther, 2010; 9(8):2344-53. MCT-1510-0324.

Petrov A, Kasatochkin A, Emelina E. Study of regioselectivity of reactions between 3 (5)-aminopyrazoles and 2-acetylcycloalkanones. Russ J Organ Chem, 2012; 48(8):1111-20.

Petrova O, Sobenina L, Demenev A, Mikhaleva A, Ushakov I. Synthesis of functionalized 2-(2-Pyrrolyl) pyrazolo [1, 5-a] pyrimidines. Russ J Organ Chem, 2003; 39(10):1471-6.

Quiroga J, Portilla J, Abonía R, Insuasty B, Nogueras M, Cobo J. Synthesis of novel 5-amino-1-aroylpyrazoles. Tetrahedron Lett, 2008; 49(41):5943-5.

Reimlinger H, Peiren MA, Merényi R. Synthesen mit heterocyclischen Aminen, I. Reaktionen des 3 (5)-Amino-pyrazols mit $\alpha, \beta$-ungesättigten Estern. Darstellung und Charakterisierung isomerer Oxo-dihydro-pyrazolo-pyrimidine. Chemische Berichte, 1970; 103(10):3252-65.

Reynolds A, Hanani R, Hibbs D, Damont A, Pozzo ED, Selleri S, Dollé F, Martini C, Kassiou M. Pyrazolo[1,5-a]pyrimidine acetamides: 4-Phenyl alkyl ether derivatives as potent ligands for the $18 \mathrm{kDa}$ translocator protein (TSPO). Bioorgan Med Chem Lett, 2010/10/01/ 2010; 20(19): 5799-802.

Schenone S, Bruno O, Bondavalli F, Ranise A, Mosti L, Menozzi G, Fossa P, Manetti F, Morbidelli L, Trincavelli L. Synthesis of 1-(2-chloro-2-phenylethyl)-6-methylthio-1H-pyrazolo [3, 4-d] pyrimidines 4-amino substituted and their biological evaluation. Eur J Med Chem, 2004; 39(2):153-60

Selleri S, Bruni F, Costagli C, Costanzo A, Guerrini G, Ciciani G, Costa B, Martini C. 2-Arylpyrazolo[1,5-a]pyrimidin-3-yl acetamides. New potent and selective peripheral benzodiazepine receptor ligands. Bioorgan Med Chem, 2001/10/01/2001; 9(10):2661-71.

Vogel A, Troxler F. Neue Synthesen von Pyrazolo [1, 5-a]-striazinen. Helv Chim Acta, 1975; 58(3):761-71.

Winters G, Sala A, De Paoli A, Ferri V. Easy synthesis of new ring-fused pyridones from heteroaromatic $\beta$-vinylamines. Synthesis, 1984; 1984(12):1052-4

Wu YC, Zou XM, Hu FZ, Yang HZ. Design and synthesis of novel sulfone-containing pyrazolo $[1,5$-a]-pyrimidines and pyrazolo $[5,1-\mathrm{d}]$ $[1,2,3,5]$ tetrazine-4 (3H)-ones. J Heterocycl Chem, 2005; 42(4):609-13.

Zaharan MA, El-Sharief AMS, El-Gaby MS, Ammar YA, ElSaid UH. Some reactions with Ketene dithioacetals: Part I: Synthesis of antimicrobial pyrazolo [1,5-a] pyrimidines via the reaction of ketene dithioacetals and 5-aminopyrazoles. Il Farmaco, 2001; 56(4):277-83.

\section{How to cite this article:}

Mohamed MS, Mahmoud AM. Believes versus evidencebased regio-orientation in the structure assignment of pyrazolo[1,5-a]pyrimidines. J Appl Pharm Sci, 2019; 9(11):126-144. 